Research Article

\title{
Study on Adaptive Excitation System of Transmission Line Galloping Based on Electromagnetic Repulsive Mechanism
}

\author{
Jiangjun Ruan $\mathbb{D}^{\mathbb{D}},{ }^{1}$ Li Zhang $\mathbb{D}^{1},{ }^{1}$ Wei Cai, ${ }^{2,3}$ Daochun Huang, ${ }^{1}$ Jian Li, ${ }^{2,3}$ and Zhihui Feng ${ }^{2,3}$ \\ ${ }^{1}$ School of Electrical Engineering and Automation, Wuhan University, Wuhan 430072, China \\ ${ }^{2}$ Wuhan NARI Limited Liability Company, State Grid Electric Power Research Institute, Wuhan 430074, China \\ ${ }^{3}$ Hubei Key Laboratory of Power Grid Lightning Risk Prevention, Wuhan 430074, China \\ Correspondence should be addressed to Jiangjun Ruan; ruan308@126.com
}

Received 11 May 2021; Revised 24 August 2021; Accepted 23 September 2021; Published 25 October 2021

Academic Editor: S bastien Besset

Copyright (c) 2021 Jiangjun Ruan et al. This is an open access article distributed under the Creative Commons Attribution License, which permits unrestricted use, distribution, and reproduction in any medium, provided the original work is properly cited.

\begin{abstract}
Due to the uncontrollable weather conditions, it is difficult to carry out the controllable prototype test to study fatigue damage of transmission tower and armour clamp and the effect evaluation of antigalloping device under actual transmission line galloping. Considering the geometric nonlinearity of the transmission line system, this study proposed an adaptive excitation method to establish the controllable transmission line galloping test system based on the Den Hartog vertical oscillation mechanism. It can skip the complicated process of nonlinear aerodynamic force simulation. An electromagnetic repulsion mechanism based on the eddy current principle was designed to provide periodic excitation for the conductor system according to the adaptive excitation method. The finite element model, including conductor, insulator string, and electromagnetic mechanism, was established. Newmark method and fourth-order Runge-Kutta algorithm were used to complete the integrated simulation calculation. By comparing with the measured data record of the actual transmission line galloping test, the results show that the proposed adaptive galloping excitation system can effectively reconstruct the key characteristics of the actual transmission line galloping, such as amplitude, frequency, galloping mode, and dynamic tension, and make the galloping state controllable. Thus, a series of research about transmission line galloping with practical engineering significance can be carried out.
\end{abstract}

\section{Introduction}

With the rapid development of power grid and the frequent occurrence of severe weather, the frequency and the extent of damage caused by the transmission line galloping are increasing obviously. It is generally believed that galloping is a large-scale and low-frequency self-excited vibration caused by the change in aerodynamic parameters after the conductor is covered with ice. It is easy to cause phase-to-phase short-circuit fault, trips caused by flashovers, damage of armour clamps, spacers, transmission towers, or even tower collapse, which seriously threaten the safe and stable operation of the power grid. Therefore, it is necessary to establish the transmission line galloping test system to explore the influence of galloping on conductors and towers, armour clamp, and components of the transmission line system. It has important engineering practical application to further understand galloping and even put forward measures to prevent galloping [1-3].

Remarkable achievements have been made from a lot of research on galloping mechanisms [4-6], experiments [7-10], numerical simulation [11-19], antigalloping devices, and field monitoring [20] carried out by researchers around the world. In terms of galloping numerical simulation, Desai et al. $[12,13]$ decomposed galloping into lateral motion and torsional motion, established a two-degree-of-freedom galloping model, and analysed the galloping response of the bundled transmission line. Based on the three-node parabolic clue element and the two-node Euler beam element proposed by $\mathrm{Yu}$, the finite element model for the galloping of ice-coated split conductors was established by Liu et al. [14], and the influence of the subconductor wake interference effect on the galloping has been studied. Li et al. [15] proposed a galloping finite element method based on two-node 
cable elements with torsional degrees of freedom and studied the galloping response characteristics of multigap ice-coated transmission lines. $\mathrm{Hu}$ et al. [16-18] used ABAQUS Euler beam element to carry out the galloping numerical simulation of the real test transmission lines. The galloping pattern, amplitude, and dynamic tension of the conductor were consistent with the actual measured results.

The galloping test research is mainly divided into wind tunnel tests and prototype test. The former is mainly to obtain the aerodynamic coefficient of the conductor, explore the aerodynamic characteristics of the conductor under various icing sections, and explore the influence of wind attack angle, wind speed, and line cross section on transmission line galloping [10]. In terms of prototype test, Japan [21], Canada [22], China [23], and the like have established full-scale test lines with multiple types of split conductors, and artificial ice-coating models have been installed in some test lines to simulate galloping. The galloping frequency, amplitude, dynamic tension, wind, and insulator string inclination have been obtained. The prototype tests have verified the effectiveness of some new antigalloping devices and have important engineering practical value for galloping research.

Due to the limitation of the size of the wind tunnel laboratory and the scale effect of the model, the aeroelastic model of the transmission tower-line system is difficult to simulate the nonlinear aerodynamic load on the ice-coated conductors. Thus, the wind tunnel test is extremely difficult and even impossible to model the galloping phenomenon of iced transmission lines [18]. For the full-scale test, due to the uncontrollability of the two key factors, ice and wind that cause the galloping, the simulation test is greatly restricted by natural conditions, the test efficiency is often not high, and it cannot used for continuous fatigue damage testing. Therefore, it is necessary to establish a test system with a controllable galloping state for actual transmission lines. Considering the geometric nonlinearity of the conductor system, this study proposes an adaptive excitation method to establish the controllable transmission line galloping test system, which no longer depends on the natural wind, skips the complex process of galloping nonlinear aerodynamic load simulation, and directly makes the static transmission line vibrate through the mechanical excitation. Through the controllable exciting force, which periodically injects positive energy into the transmission line system, the control of the galloping state is realized, and the motion characteristics and dynamic tension of the conductor during galloping are reproduced. An electromagnetic repulsion mechanism based on the eddy current principle was designed to provide periodic excitation according to the requirements. The integrated numerical simulation of the excitation system is a complex field-circuit-coupled transient problem, including structural dynamics, eddy current field simulation, and circuit simulation. The fourth-order RK algorithm and the Newmark- $\beta$ method are combined to perform numerical calculation, which improves the calculation efficiency. The excitation system can be used to test and analyse the endurance of towers, bolts, insulator strings, conductors, and fittings of the transmission line system when galloping, evaluate the antigalloping effect of interphase spacers, antigalloping devices, and so on. Based on this, a series of researches with theoretical value and practical engineering significance can be carried out.

\section{Research on Adaptive Excitation Method of Line Galloping}

2.1. Mathematical Model of Transmission Line Excitation. The circular cross section of the transmission line becomes asymmetrical due to the icing. When the wind with the speed $U$ in the horizontal direction blows on the icing conductor, the lift, drag, and torsional moment on the iced conductor are calculated as follows:

$$
\left[F_{L} F_{D} F_{M}\right]^{T}=\frac{1}{2} \rho U^{2} D\left[C_{L}(\alpha) C_{D}(\alpha) D C_{M}(\alpha)\right]^{T},
$$

where $F_{L}, F_{D}$, and $F_{M}$ are the lift, drag, and torsional moment, respectively, $\rho$ is the density of the air, $D$ is the diameter of the conductor, and $C_{L}, C_{D}$, and $C_{M}$ represent the lift coefficient, drag coefficient, and torsional moment coefficient, respectively. These coefficients are related to the cross-sectional shape of the ice-coated conductor and the wind attack angle $\alpha$.

When the transmission line galloping happens, the icecoated conductor can be regarded as a three-degree-offreedom system with vertical, lateral, and torsional vibrations at the same time. Its vertical ( $y$-direction) and lateral ( $z$-direction) vibration and torsional vibration equations under wind excitation can be deduced [24]:

$$
\begin{aligned}
m \ddot{y}+\left[2 m \zeta_{y} \omega_{y}+\frac{1}{2} \rho U^{2} D\left(\frac{\partial C_{L}}{\partial \theta}+C_{D}\right)\right] \dot{y}+k_{y} y=-m_{i} r \cos \theta_{0} \ddot{\theta}-\frac{1}{2} \rho u^{2} D C_{y} \frac{1}{U} \frac{d z}{d t}+\frac{1}{2} \rho U^{2} D C_{y} \frac{\partial C_{y}}{\partial \theta}, \\
m \ddot{z}+\left(2 m \zeta_{z} \omega_{z}+\frac{1}{2} \rho U^{2} D C_{D} \frac{1}{U}\right) \dot{z}+k_{z} z=-m_{i} r \sin \theta_{0} \ddot{\theta}+\frac{1}{2} \rho U^{2} D \frac{\partial C_{D}}{\partial \theta} \theta \\
J \ddot{\theta}+\left(2 J \zeta_{\theta} \omega_{\theta}+\frac{1}{2} \rho U^{2} D^{2} \frac{\partial C_{M} R}{\partial \theta U}\right) \dot{\theta}+\left(k_{\theta}-\frac{1}{2} \rho U^{2} D^{2} \frac{\partial C_{M}}{\partial \theta}-m_{i} r g \sin \theta_{0}\right) \theta \\
=-m_{i} r \cos \theta_{0} y-m_{i} r \sin \theta_{0} z-\frac{1}{2} \rho U^{2} D^{2} C_{M} \frac{1}{U} \dot{z}
\end{aligned}
$$


where $\theta$ and $\theta_{0}$ are the torsion angle and the initial freezing angle, respectively; $m$ and $m_{i}$ are the conductor mass and the ice mass per unit length, respectively; $J$ is the equivalent moment of inertia; $\zeta_{y}, \zeta_{z}$, and $\zeta_{\theta}$ are the damping ratio of the conductor in the vertical, transverse, and torsional directions; $k_{y}, k_{z}, k_{\theta}$ are the stiffness in the vertical, transverse, and torsional directions, respectively; $\omega_{y}, \omega_{z}$, and $\omega_{\theta}$ are the vibration frequencies in the vertical, transverse, and torsional directions, respectively; $r$ is the radius of the conductor; $C_{y}$ is the vertical wind load coefficient; $R$ is the characteristic radius, where the conductor radius $r$ can be taken.

When the damping term on the left side of the vertical vibration equation (2) is less than 0 ,

$$
2 m \zeta_{y} \omega_{y}+\frac{1}{2} \rho U^{2} D\left(\frac{\partial C_{L}}{\partial \theta}+C_{D}\right)<0 .
$$

The "negative damping" appears, and the system will generate vertical self-excited vibration. This vertical excitation galloping is also known as Den Hartog oscillation [4]. This excitation mode is a torsion-free model without torsional vibration. Similarly, when the damping term on the left side of the torsional vibration equation (4) is less than zero, the system generates torsional self-excited vibration and becomes unstable. Then, it may excite large vertical vibration through coupling, which is the coupled vertical and torsional oscillation theory proposed by Nigol and Buchan [5].

According to whether Den Hartog's vertical oscillation theory or Nigol's coupled vertical and torsional oscillation theory, the vertical instability finally appears, and it will lead to the continuous increase in the vibration amplitude of the transmission line, whereas the horizontal amplitude is a forced vibration with small amplitude, and the vibration track is generally elliptical. The frequency of vibration is close to the natural frequency of the transmission line system itself. Therefore, the galloping excitation method proposed in this study is based on the Den Hartog's vertical oscillation theory, which mechanically excites the conductor in the vertical plane, and periodically injects positive energy into the system to simulate the accumulation of energy drawn from the wind during actual transmission line galloping.

Through the controllable pulsed electromagnetic force, the impacting mechanical energy is periodically injected into the transmission line system to make it vibrate. As the injected mechanical energy continues to increase, the total kinetic energy and potential energy of the system will become larger and larger. Then, it will be a stable vibration mode due to damping at last. The energy change process is consistent with the actual transmission galloping:

$$
\Delta E_{k}+\Delta E_{p}+\int \sigma \mathrm{d} \varepsilon+Q_{d}=W .
$$

The items at the left side of the equation are the kinetic energy, gravitational potential energy, and strain energy change of the system in turn; $Q_{d}$ is the energy dissipated by the system damping, and $W$ is the work done by the external force. Due to the process of energy accumulation, the test system can simulate the actual transmission line galloping excitation and maintenance process. At the same time, it will not cause the conductors to bear excessive tension in an instant and lead to conductor breakage and tower damage. Because the amplitude and action time of the electromagnetic force are controllable, the vibration amplitude and time of the transmission line system are also controllable.

2.2. Finite Element Model of Transmission Line System. Taking an actual one-span quad bundle transmission line with a $300 \mathrm{~m}$ span as an example, we established its finite element model to explore the adaptive excitation method of transmission line galloping. The type of conductor used is LGJ-630/55, the Young's modulus is $65000 \mathrm{MPa}$, the breaking force is $164.4 \mathrm{kN}$, the cross-sectional area of a single subconductor is $696.22 \mathrm{~mm}^{2}$, and the mass per unit length is $2206 \mathrm{~kg} / \mathrm{km}$. The insulator string is XWP-400 suspension porcelain insulator; the string length is $6 \mathrm{~m}$. Considering that the excitation system adopts the mechanical excitation method, skipping the process of nonlinear aerodynamic load simulation, the wake interference of air flow around the subconductors does not need to be considered. Therefore, the quad bundle conductor is equivalent to a single conductor when modelling [25], and all simulations do not take into account the effects of wind; 200 two-node beam elements are used to model the conductor by releasing their two rotational degrees of freedom corresponding to the bending deformation at each node [16]. The insulator string is simulated by the T3D2 cable element. Rayleigh damping is used to describe the damping of a conductor line, which can be expressed as follows:

$$
C=\alpha_{d} M+\beta_{d} K .
$$

In equation (7), the matrices $C, M$, and $K$ are, respectively, the damping matrix, mass matrix, and stiffness matrix, and the parameters $\alpha_{d}$ and $\beta_{d}$ can be determined based on the equivalent viscous damping ratio and the natural frequencies of the transmission line [13].

The in-plane modal analysis result is compared with the theoretical formula calculation result to verify the correctness of the finite element model. The modal analysis results of the first four orders are shown in Table 1. The theoretical formula is as follows [24]:

$$
F_{v n}=\frac{n}{2 L} \sqrt{\frac{T}{q}}
$$

where $n$ is the order, $L$ is the span length, $T$ is tension of the conductor, and $q$ is the mass per unit length of the conductor.

It can be seen from Table 1 that the natural frequency values obtained by the finite element modal analysis and theoretical formula modal analysis are consistent, indicating the correctness of the establishment of the finite element model.

A vertical downward concentrated force load is applied to the end node of the conductor, the value is $5 \mathrm{kN}$, and the action time is $0.1 \mathrm{~s}$. Newmark- $\beta$ algorithm with self-adapting 
TABLE 1: In-plane modal analysis results of transmission line.

\begin{tabular}{lccc}
\hline Loop number & Mode shape & Frequency (theoretical calculation) $(\mathrm{Hz})$ & Frequency (FEM calculation) (Hz) \\
\hline 1 & 0.1983 & 0.1979 \\
2 & 0.3967 & 0.3954 \\
3 & 0.5950 & 0.5926 \\
4 & 0.7933 & 0.7891 \\
\hline
\end{tabular}

step size is used to calculate the vibration response of the transmission line nodes. The calculation result is shown in Figure 1.

The excitation point moves down rapidly with the loading of the end excitation. The downward displacement increases continuously from 0 to $0.2 \mathrm{~m}$ and then returns to stability after the oscillation. The excitation wave is transmitted to the other end of the line, causing similar vibration characteristics at other points on the line. After $1.25 \mathrm{~s}$, it starts to oscillate at the midpoint of the line, and after about $2.5 \mathrm{~s}$, the excitation wave is transmitted to the other end of the line, corresponding to the second-order natural frequency. Then, the excitation wave is reflected back to the excitation side, and each point on the line starts to oscillate in turn. The transmission period of the excitation wave is about $5 \mathrm{~s}$, which corresponds to the first-order natural frequency of the transmission line system.

2.3. End Excitation Method. Considering that the frequency of the actual galloping vibration is close to the natural frequency of the transmission line system itself, we simulate the actual galloping using the superimposition of excitation waves. Set the interval of each excitation to about $2.5 \mathrm{~s}$, so that there will always be two opposite half-waves on the transmission line. The half-wave and half-wave converge to increase the amplitude of conductor vibration. In the simulation, the concentrated force of each excitation is still $5 \mathrm{kN}$, and the action time is $0.1 \mathrm{~s}$. The displacement and spectrum analysis results of the excitation point and typical points of the line are shown in Figure 2.

It can be seen from Figure 2 that with this excitation method, the vibration amplitude in the vertical direction increases continuously in the first $50 \mathrm{~s}$, which is similar to the excitation process of the actual line galloping. The amplitude change is greatest at the $1 / 4$ and $3 / 4$ point of the line, which increases about $1.4 \mathrm{~m}$. The amplitude of excitation point increases to about $0.8 \mathrm{~m}$ with the continuous excitation. The amplitude variation is the smallest at the midpoint, and the vibration amplitude does not exceed $0.4 \mathrm{~m}$. The vibration amplitudes are stable for $50 \mathrm{~s} \sim 140 \mathrm{~s}$, it is the largest at positions $1 / 4$ and $3 / 4$ point of the transmission line, about $1.4 \sim 1.6 \mathrm{~m}$, and the vibration amplitude at the midpoint is the smallest, only about $0.2 \mathrm{~m}$. The vibration amplitude of the excitation point is stable at about $0.5 \sim 0.8 \mathrm{~m}$. The displacement nephogram during the stable vibration period is shown in Figure 3. The peak frequency of the amplitude spectrum of each point is approximately equal to the second natural frequency of the system. The vibration form presents a double-half-wave, which well realizes the restoration of the characteristics of Den Hartog's two-loop mode galloping.

After $140 \mathrm{~s}$, the vibration amplitude of the transmission line continues to decrease. The vibration amplitude at positions $1 / 4$ and $3 / 4$ point of the line decreased from $1.4 \mathrm{~m}$ to about $0.6 \mathrm{~m}$. Amplitude of the excitation point decreased continuously from $0.8 \mathrm{~m}$ to about $0.2 \mathrm{~m}$. Vibration amplitude at the midpoint decreased continuously from $0.2 \mathrm{~m}$ to less than $0.1 \mathrm{~m}$. This is mainly because the transmission line system is a typical nonlinear geometrical problem with large displacement and small linear elastic tensile deformation in the axial direction. As a result, the natural frequency of the line changes as the shape of the line changes. The time for the wave to pass to the other side will also change, and it may happen that the exciting force does negative work to reduce the vibration of the line. Therefore, the use of fixed time interval excitation can neither quickly excite the line galloping with the highest efficiency nor can maintain the amplitude of the line vibration.

The analysis shows that when there are two opposite excitation waves on the line, the key factor to increase the vibration amplitude to simulate the actual line galloping is to accurately capture the moment when the excitation wave is reflected back from the other side and reaches the excitation point. The interval time varies with the vibration amplitude and shape of the line. In the process of applying the same direction excitation force, the positive energy can be injected into the system to increase the amplitude. Therefore, the basis for judging the acting time of the exciting force is given: The acting time of the first exciting force is 0 , and the initial acting time of the second exciting force is about $2.5 \mathrm{~s}$ (corresponding to the second natural frequency). At the beginning of the 3 excitations, because the interval between each excitation is close to $2.5 \mathrm{~s}$, the time parameter $\alpha$ is set to help the control system accurately find the time when the excitation wave reflects from the other side to the excitation point. The displacement parameter $\beta$ and velocity parameter $\gamma$ are used to judge whether the excitation point is in the process of downward movement and location of the excitation point is within the action range of the electromagnetic device:

$$
\Delta t>\alpha \& \beta_{1}<\delta<\beta_{2} \& v<\gamma
$$

Assumed that the effective action range of the electromagnetic device is within $-0.5 \sim 0.1 \mathrm{~m}$. It can be seen from Figure 2(a) that the time of the excitation wave moving back 


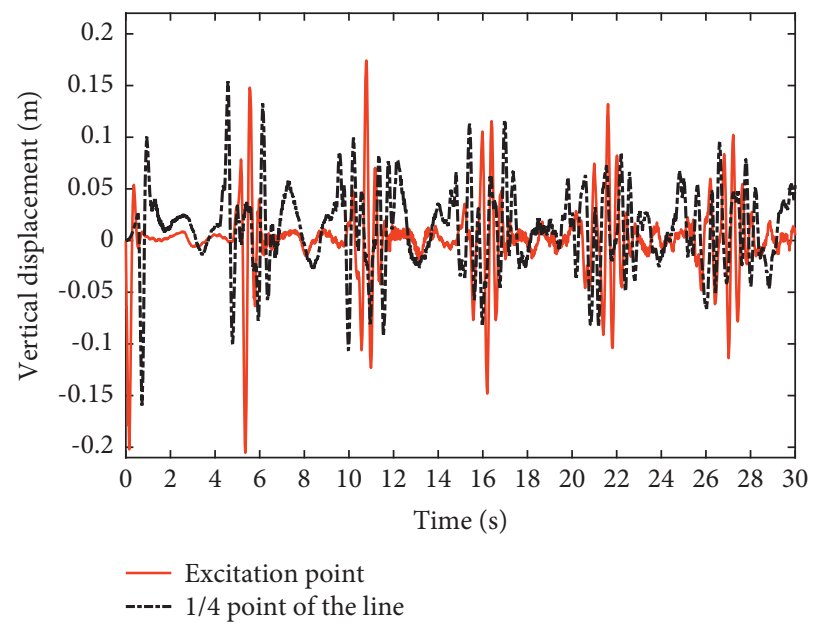

(a)

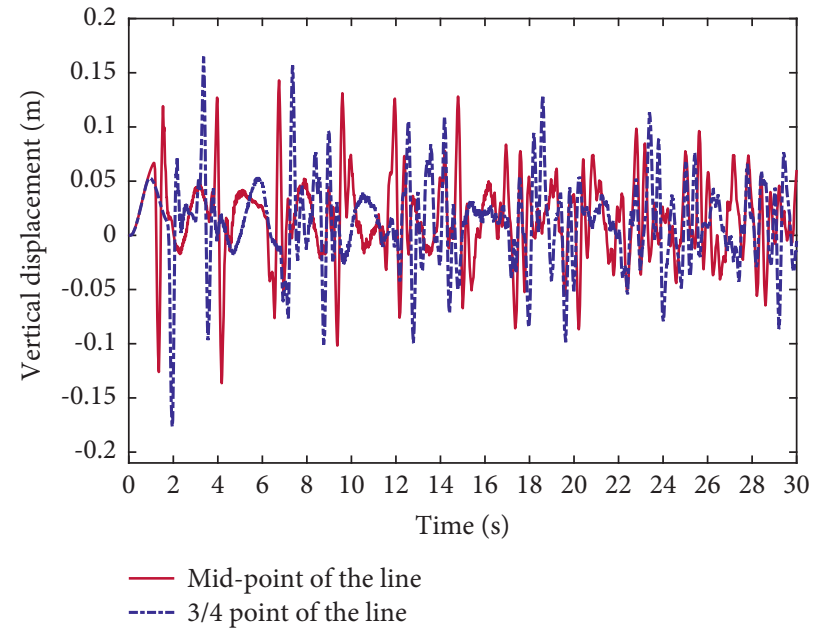

(b)

Figure 1: Displacement response after a single excitation. (a) Vertical displacement-time curve at the excitation point and 1/4 point of the line. (b) Vertical displacement-time curve at midpoint and 3/4 point of the line.

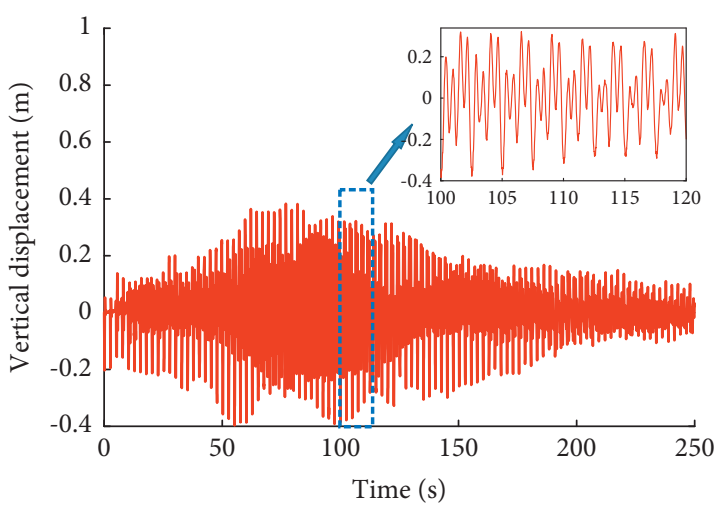

(a)

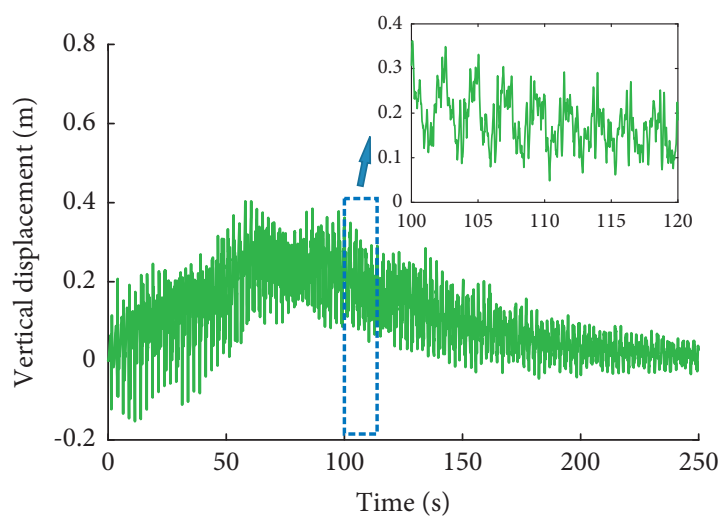

(c)

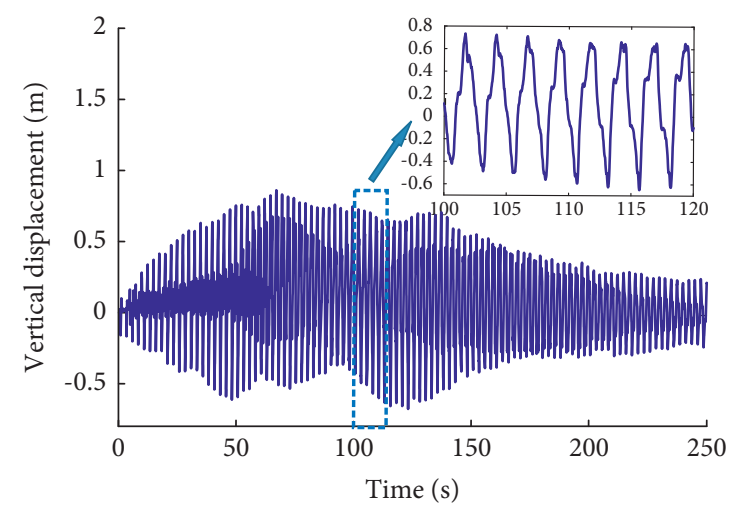

(b)

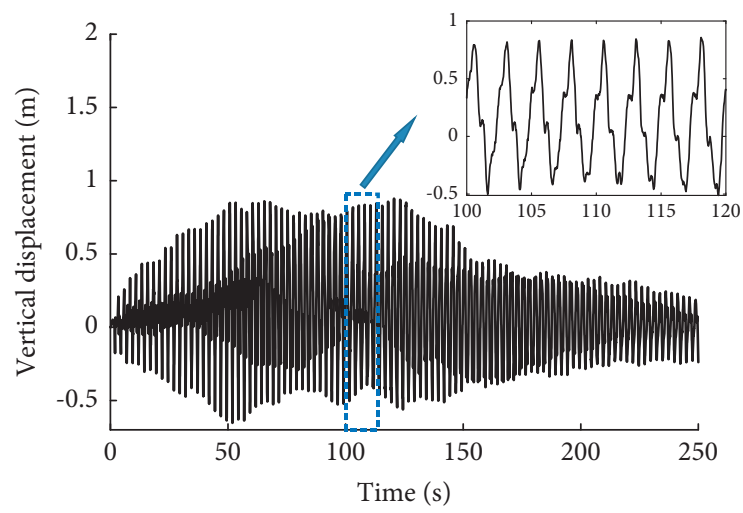

(d)

Figure 2: Continued. 


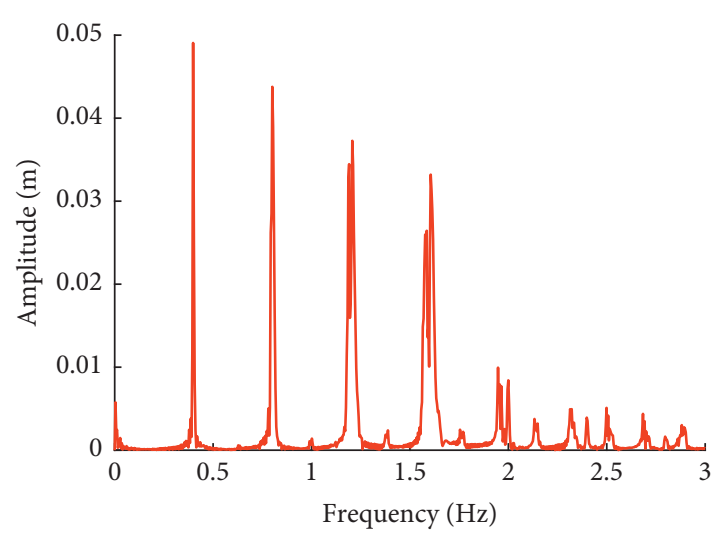

(e)

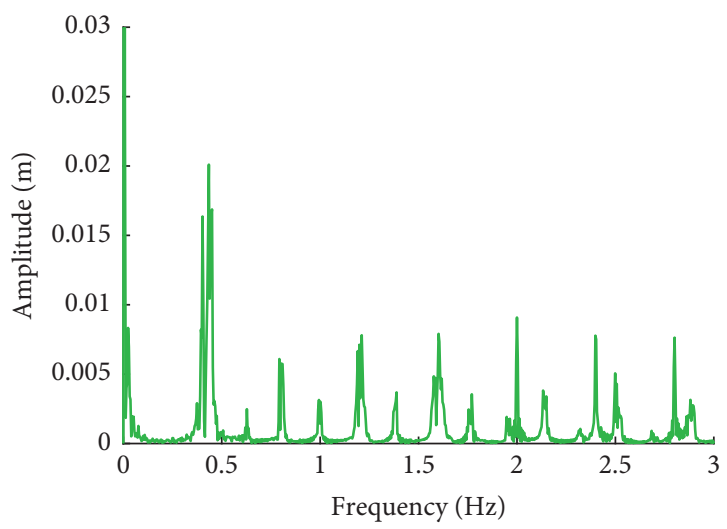

(g)

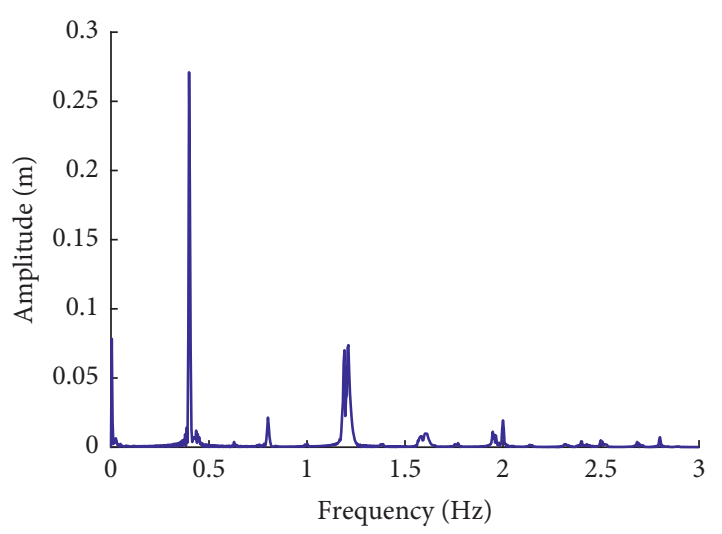

(f)

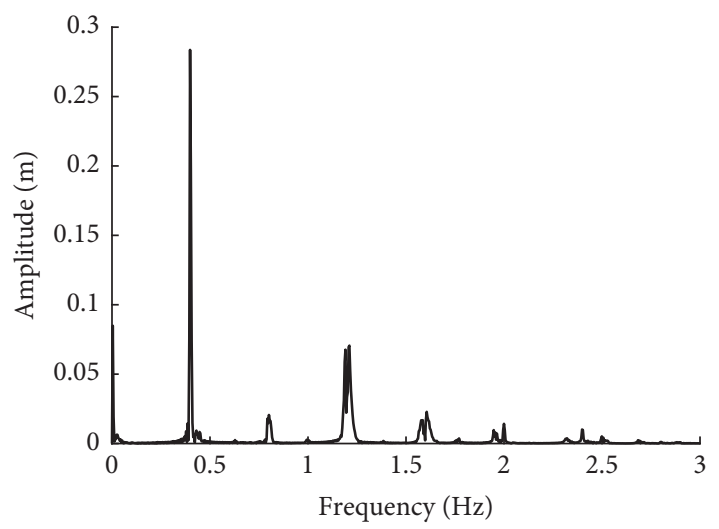

(h)

Figure 2: Finite element simulation results under excitation at fixed intervals. (a) Vertical displacement at the excitation point. (b) Vertical displacement at $1 / 4$ point of the line. (c) Vertical displacement at midpoint of the line. (d) Vertical displacement at 3/4 point of the line. (e) The amplitude spectrum at the excitation point. (f) The amplitude spectrum at $1 / 4$ point of the line. (g) The amplitude spectrum at midpoint of the line. (h) The amplitude spectrum at $3 / 4$ point of the line.
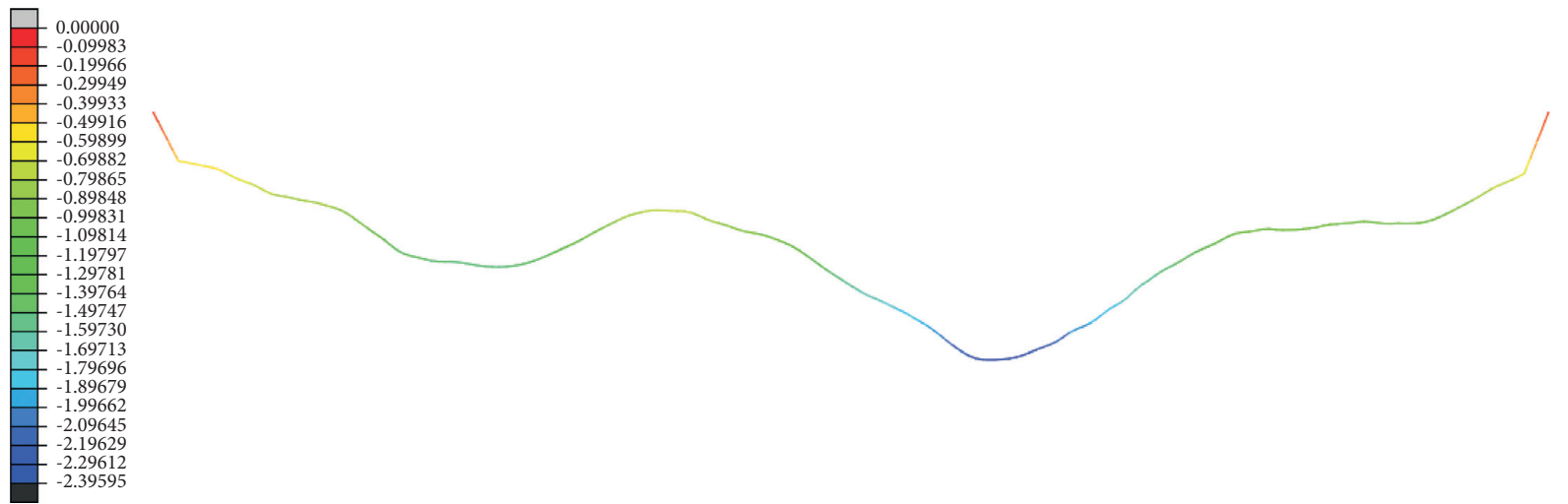

Figure 3: Displacement nephogram at a certain moment in the stable vibration stage (scaling coefficient: 20).

to the exciting point is between 2.42 and $2.82 \mathrm{~s}$, so take $\alpha=2.42, \beta_{1}=0.04, \beta_{2}=0.1$, and $\gamma=-0.04$ and use the above judgment conditions to carry out the finite element dynamic simulation calculation of the transmission line vibration. When it is monitored that the excitation force needs to be applied, downward concentrated force is applied at the end of the line, the magnitude is still $5 \mathrm{kN}$, and the action time of each excitation is $0.1 \mathrm{~s}$. Because the maximum amplitude of the two-loop mode vibration appears at the positions of $1 / 4$ and $3 / 4$ point of the line, the displacement time history curve 


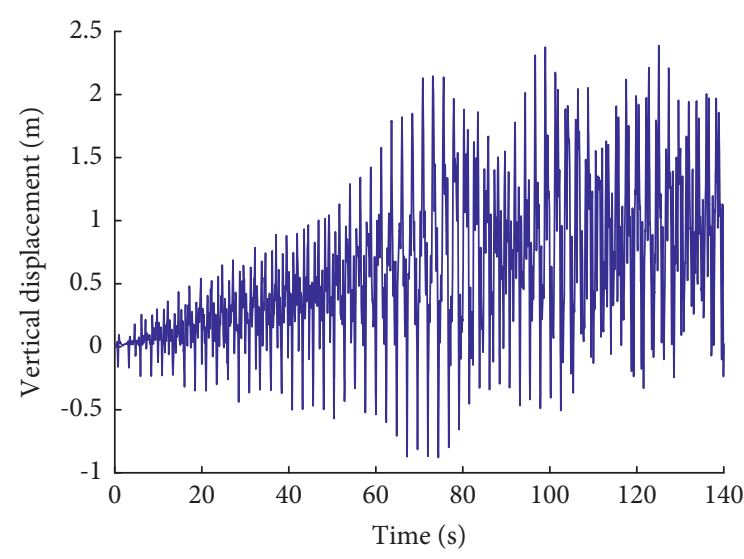

(a)

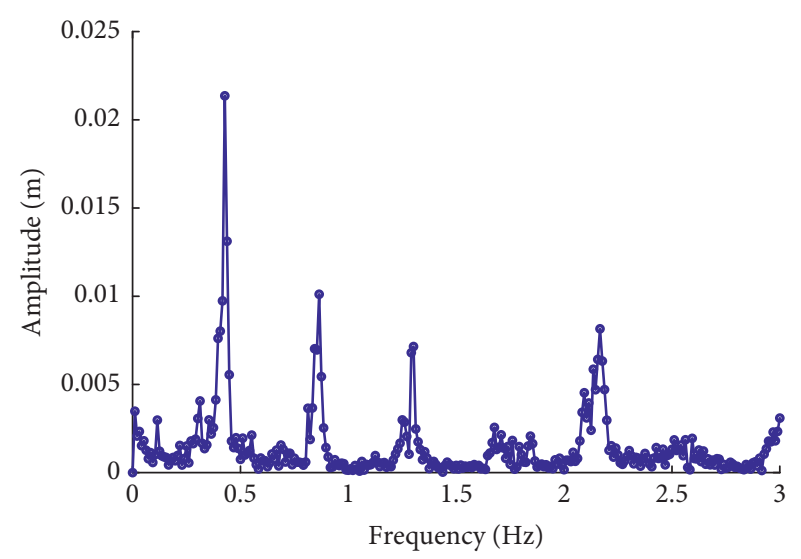

(b)

FIgURE 4: Results of $1 / 4$ point of the line under adaptive excitation. (a) Vertical displacement-time curve. (b) Amplitude spectrum.

and spectrum analysis results at $1 / 4$ point of the line are shown in Figure 4.

As can be seen from Figure 4, the vibration amplitude of the transmission line can indeed be increased quickly and effectively according to this excitation method. The vibration amplitude of the line increases rapidly within $0 \sim 70 \mathrm{~s}$, and the amplitude reaches the peak at about $70 \mathrm{~s}$. Vertical vibrate displacement at $1 / 4$ point of the line is within $-0.83 \sim 2.14 \mathrm{~m}$, the maximum vibration amplitude reaches $2.97 \mathrm{~m}$, which is much larger than the abovementioned simulation results under fixed time interval excitation. After $70 \mathrm{~s}$, the vibration amplitude continued to decrease and increase, and the amplitude fluctuates within about $2 \sim 2.97 \mathrm{~m}$. The obvious peak frequency of the vertical displacement is about $0.42 \mathrm{~Hz}$, which is close to the second natural frequency $(0.3954 \mathrm{~Hz})$. Therefore, this adaptive excitation method can effectively simulate the actual line galloping, and the amplitude of vibration is maintained within a certain range.

\section{Comparison with Field Test Results under Random Wind}

The proposed adaptive excitation method can effectively increase the vibration amplitude of the transmission line. But to establish the controllable transmission line galloping test system, it is necessary to verify that the proposed method can help to simulate the relevant characteristics of actual transmission line galloping and control the vibration amplitude within a certain range for a long time. In this section, we take a $500 \mathrm{kV}$ transmission test line as an example, the vibration response under long-time adaptive excitation is compared with the galloping field test record under the natural wind. The vibration amplitude, frequency, vibration mode, and dynamic tension of the test line are analysed.

3.1. Overview of the Actual Test Transmission Line. The real transmission test line integrated base was established in Jianshan, Henan Province, and put into use in August
2010. Transmission line galloping and its prevention and control technology are the main research contents about this test line. The total length of the test line is $3,715 \mathrm{~m}$, with 10 towers, and the span is between 157 and $657 \mathrm{~m}$. The artificial D-shape PVC plastic ice model was installed on the section of test 6-bundle conductor line between Tower 3 and Tower 4 for the galloping test research, as shown in Figure 5. Transmission line galloping under natural wind load were observed and successfully recorded [26, 27].

The span length of the line cable is $284 \mathrm{~m}$, and the height difference is $18.28 \mathrm{~m}$. The type of the six-split conductor is LGJ-300/40, the subconductor spacing is $375 \mathrm{~mm}$, and the physical and mechanical parameters of the conductor are shown in Table 2. The equivalent circular cross section is used to simulate the real cross section of the ice-coated conductor, and the ice coating is assumed to be evenly distributed along the line. The detailed equivalent method can be found in the study by $\mathrm{Hu}$ et al. [16], and the equivalent mechanical parameters of the iced transmission line are listed in Table 3.

The finite element model of the line cable is established. The comparison between the static calculation results and the measured results under the actions of self-weight is shown in in Table 4. The first-order and second-order natural frequencies and static tension are very close to the measured values. It is believed that the finite element model of the transmission line system can simulate the actual line well.

3.2. Field Test Record under the Natural Wind. The D-shaped artificial icing model was installed on the surface of the test line, and the vibration track of the typical point of the line was measured by the monocular measurement technology. At the same time, the time history of the conductor tension near the connection of tower 3 is recorded. The schematic diagram of the position of some monitoring points on the test line is shown in Figure 6. Although the wind speed and direction of the natural wind have been fluctuating, the vibration state of the conductor will not change greatly in a 


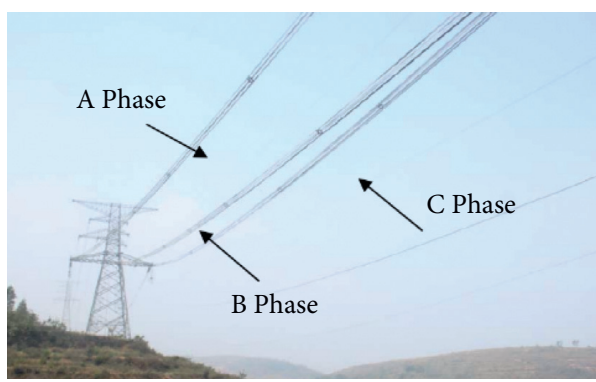

(a)

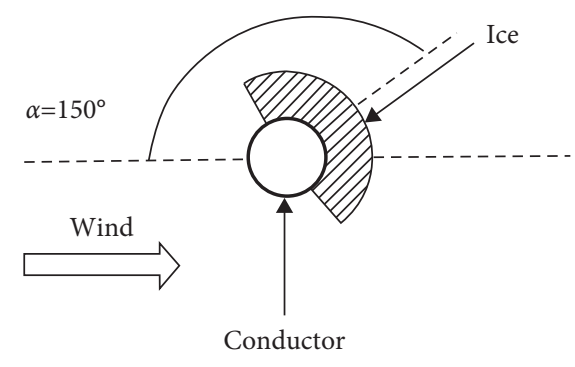

(b)

Figure 5: Full-scale transmission test lines and iced conductor. (a) Picture of the test tower-line test system. (b) Artificial D-shaped icing model.

TABLE 2: Mechanical parameters of LGJ-300/40 conductor.

\begin{tabular}{lccc}
\hline Diameter $(\mathrm{mm})$ & Mass per unit length $(\mathrm{kg} / \mathrm{km})$ & Young's modulus $(\mathrm{MPa})$ & Poisson's ratio \\
\hline 23.94 & 1133 & 73000 & 0.3 \\
\hline
\end{tabular}

TABLE 3: Equivalent mechanical parameters of D-shaped ice-covered conductors.

\begin{tabular}{lccc}
\hline Diameter $(\mathrm{mm})$ & Density $\left(\mathrm{kg} / \mathrm{m}^{3}\right)$ & Young's modulus $(\mathrm{MPa})$ & Shear modulus $(\mathrm{MPa})$ \\
\hline 46.52 & 1116.2 & 15510 & 1877 \\
\hline
\end{tabular}

TABLE 4: Finite element simulation results compared with the measured values under gravity.

\begin{tabular}{lccc}
\hline Parameter & Measured data & FE simulation value & Error (\%) \\
\hline Static tension & $106 \mathrm{kN}$ & $107.54 \mathrm{kN}$ & 1.45 \\
First-order natural frequency & $0.163 \mathrm{~Hz}$ & $0.167 \mathrm{~Hz}$ & 2.45 \\
Second-order natural frequency & $0.332 \mathrm{~Hz}$ & $0.33204 \mathrm{~Hz}$ & 0.012 \\
\hline
\end{tabular}

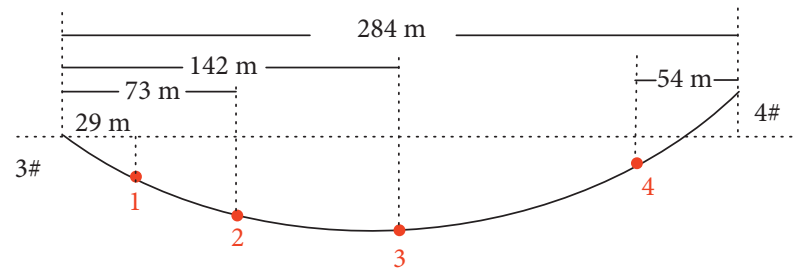

FIGURE 6: Location illustration of the monitoring points.

short time. Select a period of time when the vibration is relatively stable, the field displacement records and spectrum analysis results of each monitoring point are shown in Figure 7.

From the measured displacement time history of each measuring point, it can be seen that the vertical vibration amplitude of measuring point 1 is about $1.3 \sim 1.5 \mathrm{~m}$; the amplitude of measuring point 2 and point 4 is larger, and the maximum amplitude in the vertical direction is about $1.6 \sim 1.8 \mathrm{~m}$. The vertical amplitude recorded at point 3 stabilized at about $1.1 \mathrm{~m}$. The horizontal amplitude of each point is relatively small, about $0.4 \sim 0.5 \mathrm{~m}$. Generally speaking, the vibration amplitude near the $1 / 4$ point of the line is larger, and the vertical displacement at midpoint of the line is smaller. From the results of spectrum analysis, the vertical vibration of each measuring point has an obvious peak near $0.333 \mathrm{~Hz}$, which is close to the natural frequency of two-loop mode in the vertical displacement. The horizontal vibration of each measuring point is forced vibration, and the peak value is concentrated around $0.333 \mathrm{~Hz}$. In addition, the vertical displacement spectrogram of each measuring point has a small peak near the frequency of $0.65 \mathrm{~Hz}$, which is close to the fourth natural frequency of four-loop mode in the vertical displacement. Therefore, this test line galloping is mainly manifested as a two-loop mode, and the vibration contains four-loop mode components. It forms a stagnant point near the midpoint of the span, so that the vertical vibration amplitude of the midpoint of the line is less than the amplitude of other measuring points.

3.3. Vibration Response under Adaptive Excitation. The method of adaptive excitation proposed in this study is used to excite the end of the six-split test transmission line, and the monitoring results are compared with the field test record. The excitation point is selected near the end node of the conductor, and the vibration amplitude at $1 / 4$ point of the line is used as the control parameter of the line galloping 

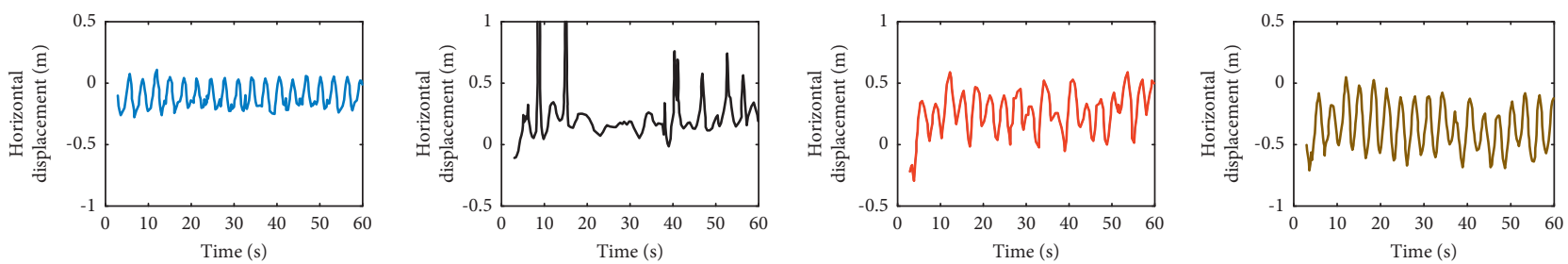

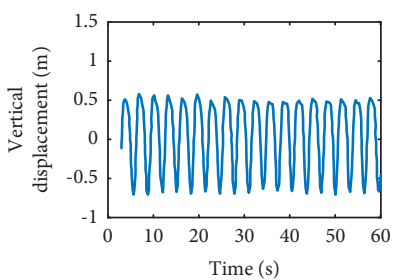

(a)
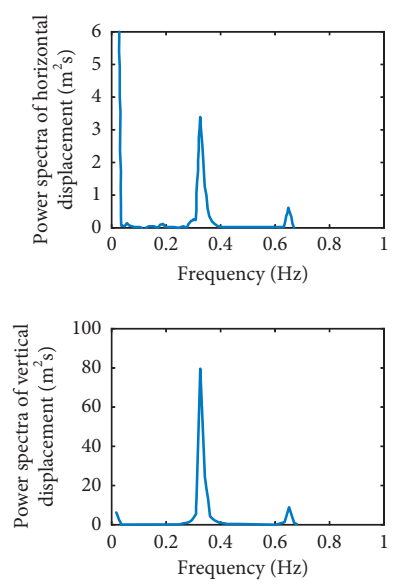

(e)

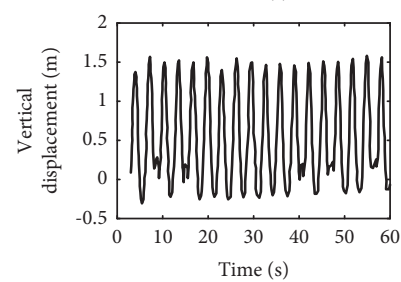

(b)
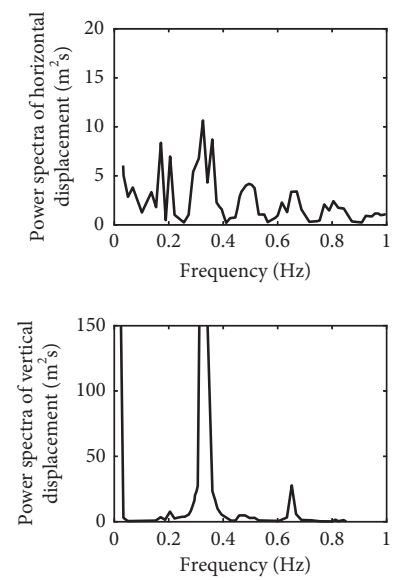

(f)

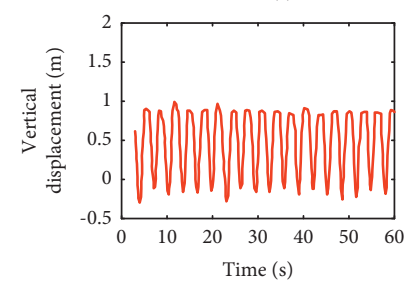

(c)
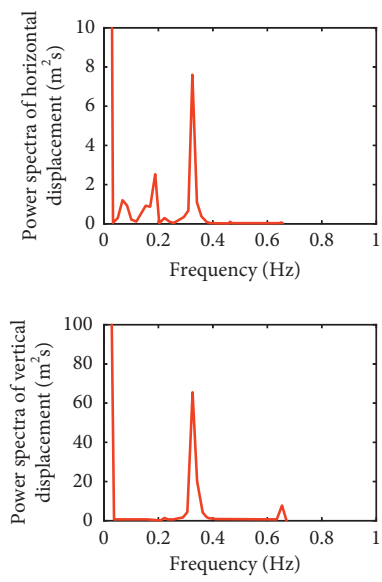

(g)

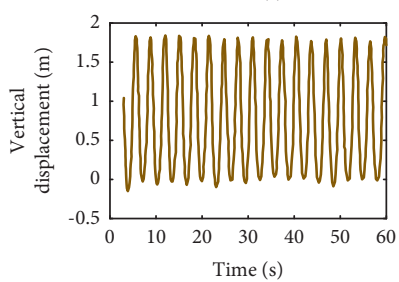

(d)
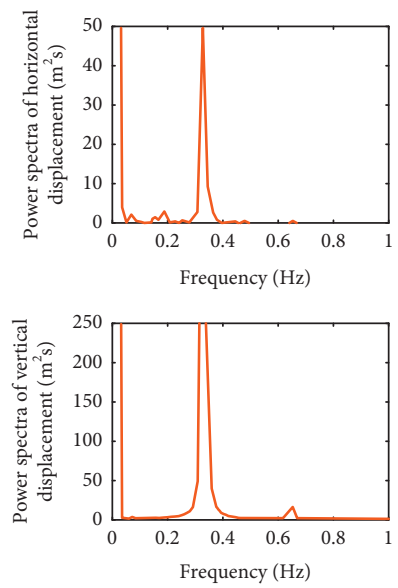

(h)

FIGURE 7: Measured data record of real transmission line galloping test. (a) Horizontal and vertical displacement time history curves of measuring point 1. (b) Horizontal and vertical displacement time history curves of measuring point 2. (c) Horizontal and vertical displacement time history curves of measuring point 3. (d) Horizontal and vertical displacement time history curves of measuring point 4. (e) Displacement spectrum at measuring point 1. (f) Displacement spectrum at measuring point 2. (g) Displacement spectrum at measuring point 3. (h) Displacement spectrum at measuring point 4.

amplitude. Referering the measured and recorded data of the vertical displacement of each monitoring point, it is expected that the amplitude of the simulated line vibration is stable in the range of $1.6 \pm 0.2 \mathrm{~m}$. The electromagnetic force is set to $6 \mathrm{kN}$, and each excitation time is $0.1 \mathrm{~s}$.

When the vibration amplitude at the $1 / 4$ point of the line exceeds $1.8 \mathrm{~m}$, the application of excitation force is stopped, and the vibration amplitude decreases immediately. When the vibration amplitude is less than $1.4 \mathrm{~m}$, the vibration application criterion is judged according to the exciting point displacement, speed, and other parameters to excite the transmission system to increase the vibration amplitude until it exceeds $1.8 \mathrm{~m}$ again. This process is repeated to keep the vibration amplitude of the conductor within a certain range. Set $\alpha=2.82, \beta_{1}=0.01, \beta_{2}=0.1$, and $\gamma=-0.5$, and set the simulation duration to $400 \mathrm{~s}$. Using this excitation strategy, the displacement time history curve and spectrum analysis results of each measuring point of the line are shown in Figure 8.
The vertical vibration amplitude of measuring points 1 , 2 , and 4 increased continuously to about $1.8 \mathrm{~m}$ in the first $70 \mathrm{~s}$. At the same time, the vertical vibration amplitude of measuring point 3 increased to $1.1 \mathrm{~m}$. During the $70 \sim 400 \mathrm{~s}$, it turns to the vibration maintenance stage, the vertical vibration amplitude of measuring points 1, 2, and 4 fluctuates between 1.4 and $2.1 \mathrm{~m}$, and measuring point 3 , which is the midpoint of the line, has a small vibration amplitude in the vertical direction and is maintained within the range of $0.4 \sim 1.0 \mathrm{~m}$. It conforms to the characteristics of two-loop mode line galloping. The amplitude of each measuring point in the horizontal direction is within $0.4 \mathrm{~m}$. The vertical and horizontal displacement spectra of each measuring point have two peaks at $0.34 \mathrm{~Hz}$ and $0.68 \mathrm{~Hz}$. Most of the main peaks of the measuring points are close to the second-order natural frequency in the vertical direction, indicating that the galloping of the conductor is mainly a two-loop mode with a small four-loop response, which is consistent with the field measured data. 

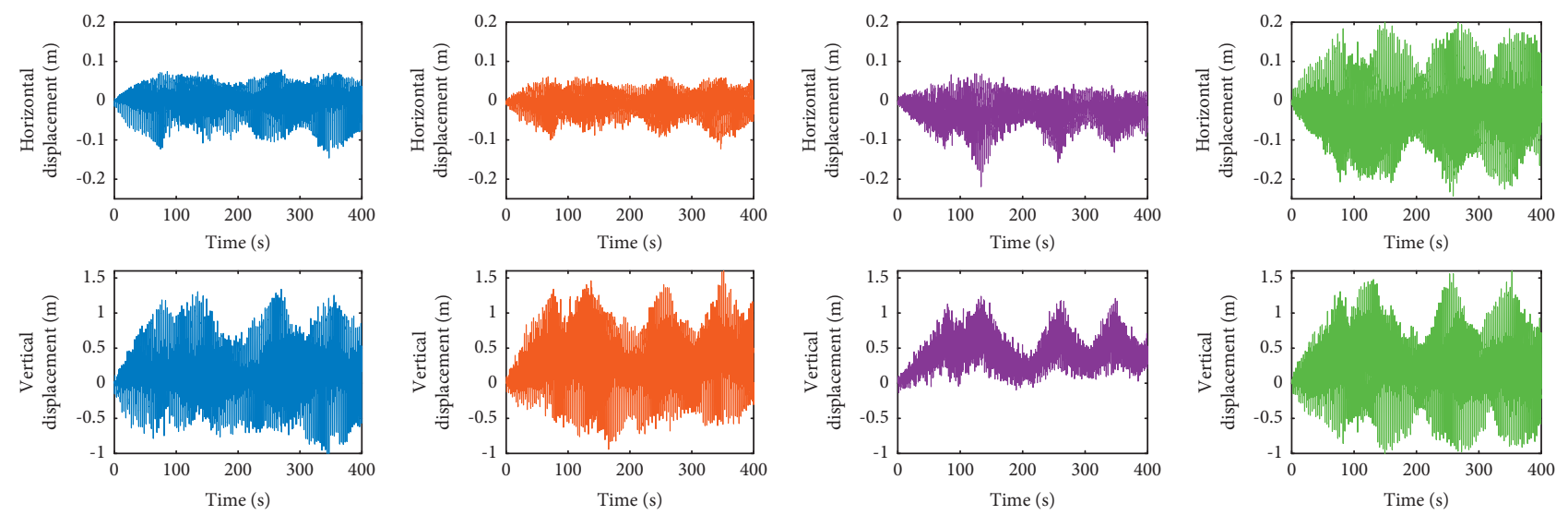

(a)

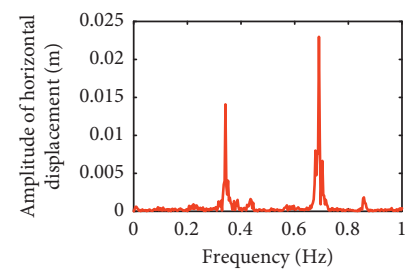

(b)

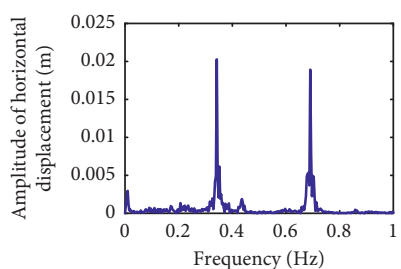

(c)

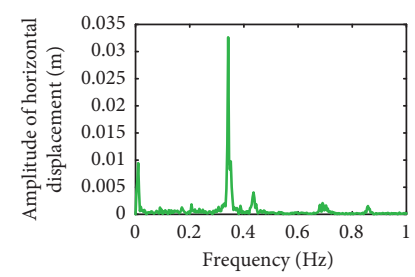

(d)

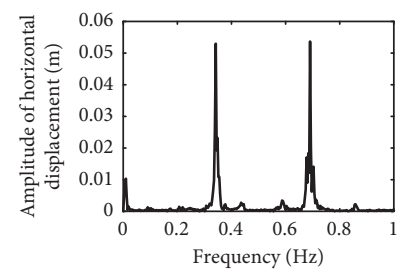

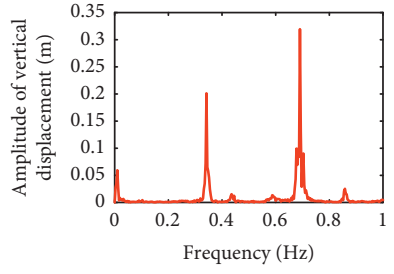

(e)

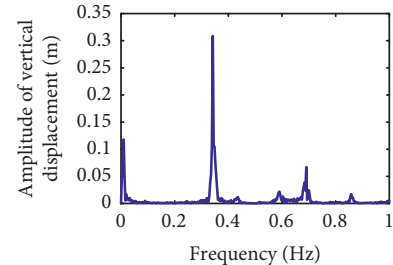

(f)

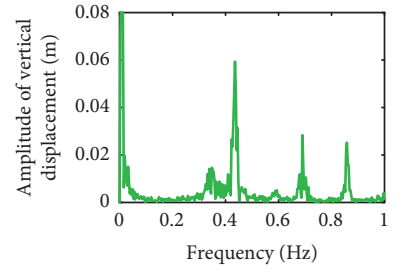

(g)

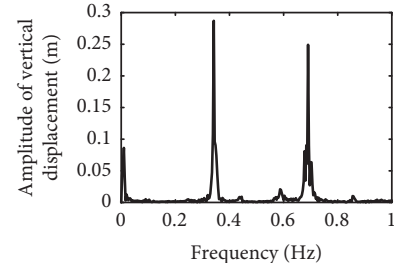

(h)

FiguRE 8: Vibration response under adaptive excitation. (a) Horizontal and vertical displacement time history curves of measuring point 1. (b) Horizontal and vertical displacement time history curves of measuring point 2. (c) Horizontal and vertical displacement time history curves of measuring point 3. (d) Horizontal and vertical displacement time history curves of measuring point 4. (e) Displacement spectrum at measuring point 1. (f) Displacement spectrum at measuring point 2. (g) Displacement spectrum at measuring point 3. (h) Displacement spectrum at measuring point 4 .

The measured value of the conductor tension at rest is $106 \mathrm{kN}$. The ratio of the dynamic tension and the static tension of the conductor during the galloping process is defined as the relative tension coefficient. The measured dynamic relative tension coefficient and the coefficient variation curve under the adaptive excitation with time are shown in Figure 9.

The dynamic tension range of the test line galloping field records is between about $101 \mathrm{kN}$ and $114 \mathrm{kN}$. The dynamic tension of the conductor based on adaptive excitation varies from $98 \mathrm{kN}$ to $122 \mathrm{kN}$. The change of tension amplitude obtained by numerical simulation under adaptive excitation is slightly larger than the value recorded on site, but the overall difference is not significant. The error of the transmission line tension range is less than $10 \%$.

From the analysis results of the displacement time history curve, the galloping amplitude in the vertical direction of the two are almost the same, and the horizontal amplitude under the adaptive excitation is slightly smaller than the field record result. From the spectrum analysis results, the spectrum analysis of both shows that the main peak is close to the second natural frequency of two-loop mode in the vertical displacement, and it also contains fourloop mode components. From the dynamic relative tension coefficient curve with time, the range of the dynamic tension of the two are almost the same. It is shown that the proposed adaptive excitation method in this study can effectively simulate the key characteristics of the actual transmission line galloping, such as vibration amplitude, frequency, vibration mode, and dynamic tension. Also, it can help to control the vibration amplitude within a certain range for a long time.

\section{Designs of the Transmission Line Galloping Excitation System}

4.1. Principle and Configuration of the Excitation System. Taking the actual test transmission line in Henan Province, China, as an example, the excitation force required for excitation is about $5 \sim 10 \mathrm{kN}$, and the action time should be ensured during the downward movement of the conductor end of each cycle (within 0.2 0.3 s). The excitation interval 


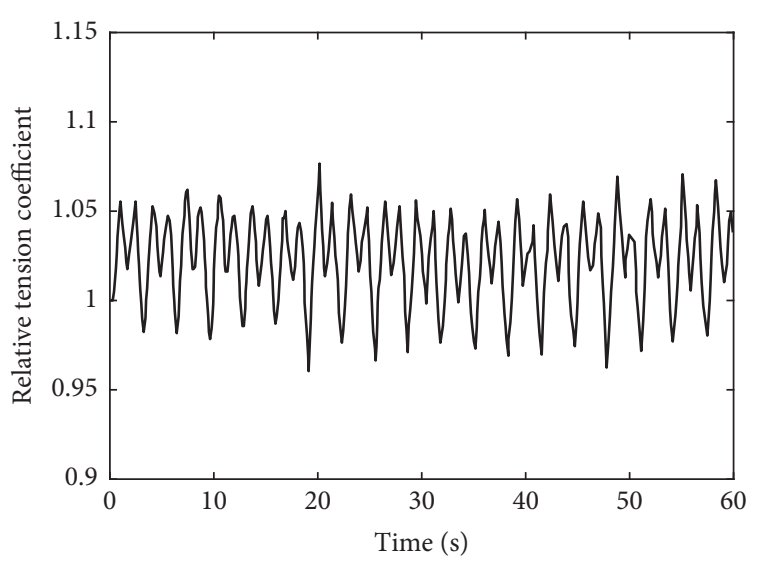

(a)

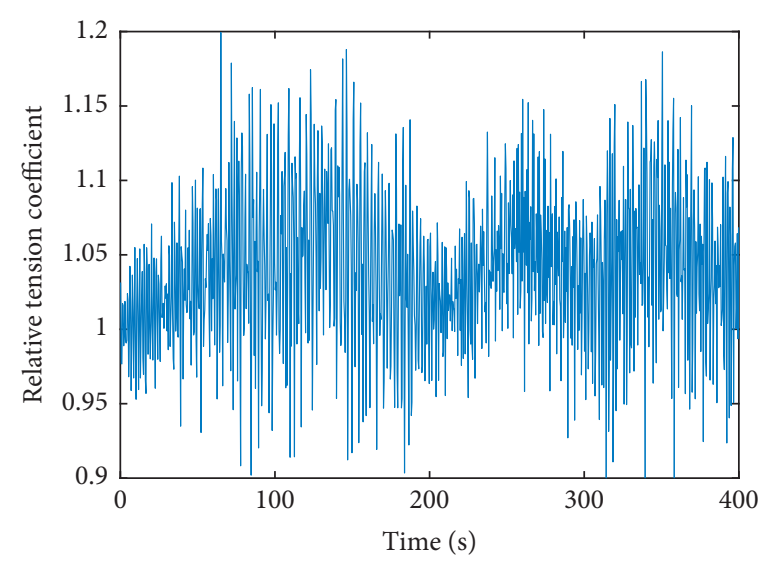

(b)

Figure 9: Dynamic relative tension coefficient variation curve with time: (a) field test record. (b) Simulation results under the adaptive excitation proposed in this article.

time should be determined based on signals such as the displacement and speed of the excitation point. For this kind of high-power and force controllable excitation device, because the current is easy to control, an electromagnet or a repulsive force mechanism based on the induced eddy current can generally be used. According to the proposed adaptive excitation method, the transmission line galloping excitation system consists of three parts: vibration monitoring, control, and electromagnetic output device. The schematic diagram is shown in Figure 10.

The transmission line galloping excitation test system includes sensors, high-power electromagnetic output device, signal line, DAQ device, computer, switch group, support frame, and other components. The sensors are used to monitor the conductor vibration data, and then, monitoring voltage signal is input to the DAQ device and the computer. After the analysis of the data according to the above adaptive excitation method, the DAQ device sends a PWM signal to control switch on and off, so that the electromagnetic output device generates periodic pulse electromagnetic force to make the conductor vibration.

As to the electromagnetic output device, the electromagnet with long stroke and large output is difficult to design, and the cost is too high. Because the force required is the pulsed electromagnetic force, it is impractical to cutoff the large current of the large inductor repeatedly. Thus, the eddy current repulsion mechanism can be used as the traction device of this transmission line galloping test system. The design schematic diagram of the highpower electromagnetic output device based on the eddy current repulsion mechanism is shown in Figure 11. After the solenoid coil is switched on, the pulse power supply will load the stored electromagnetic energy to the coil in a short time (ms level). The transient magnetic field generated by the coil current will induce eddy currents mainly composed of the circumferential component in the conductor armature. The interaction between the radial component of the magnetic field and the eddy current

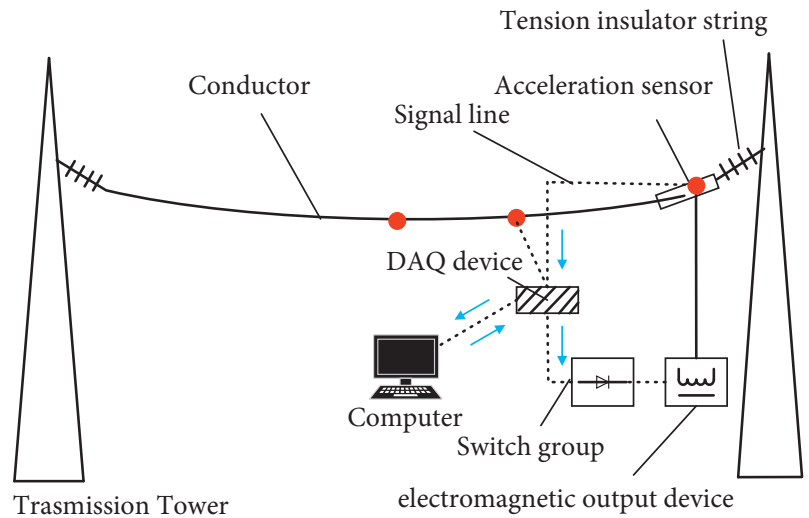

FIGURE 10: Galloping excitation system schematic diagram.

makes the Lorentz force on the armature dominated by the axial component, which pushes the armature to eject. The armature drives the end of the conductor to move quickly and injects positive energy into the transmission line system.

The power supply of the solenoid coil is provided by the capacitor bank. The monitoring signal is input to the controller, and the charging and discharging process of the capacitor bank is controlled by the controller. Therefore, the capacitor bank will periodically supply power to the coil and provide energy for the transmission line vibration. In order to protect the capacitor, a freewheeling diode is connected in parallel at both ends of the energy storage capacitor to prevent damage to the capacitor due to multiple charging and discharging. At the same time, paralleling the diode can also improve the utilization efficiency of the capacitor's discharge power. It can be seen from the above simulation results that the charging and discharging time interval is about $3 \mathrm{~s}$, so multiple capacitor banks can be connected in parallel to prevent the charging time from failing to meet the requirements of the mechanism. The equivalent circuit model of the mechanism is shown in Figure 12. 


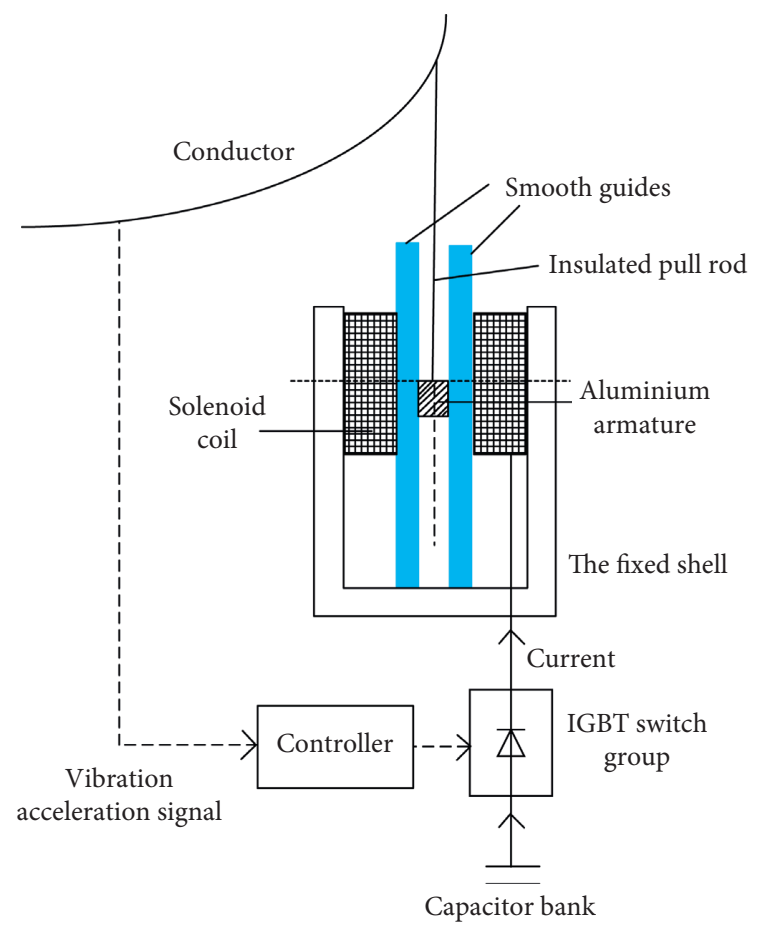

FIGURE 11: Diagram of the electromagnetic repulsion mechanism.

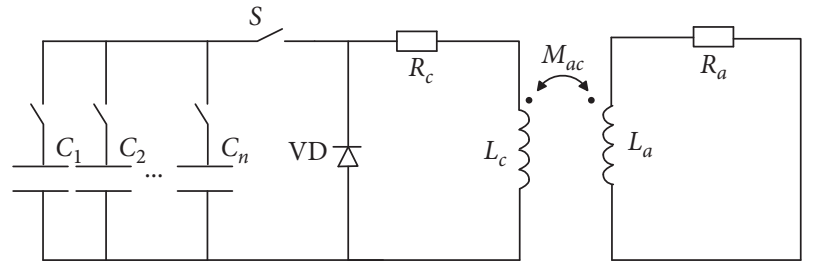

FIgURE 12: Circuit model equivalent to the mechanism.

4.2. Simulation Analysis of Single Excitation Process. The transmission line galloping excitation test system proposed in this study includes two parts: the transmission line system and the electromagnetic repulsive excitation device. The excitation device also includes a feedback control loop and an electromagnetic output device. The feedback control loop generates periodic current according to the vibration state of the conductor to supply power to the solenoid coil. Under the action of electromagnetic force, the armature drives the conductor to move, and the motion of the armature is always consistent with the motion of the excitation point of the line. Because the quality of the armature relative to the conductor and insulator string is very small, it is ignored in the calculation. When the armature position changes, the mutual inductance between the coil and the aluminium armature will change, which will affect the coil current and inductive eddy current changes and eventually lead to the change of the electromagnetic force. In turn, the conductor vibration changes the armature position and the electromagnetic force, so it is a two-way coupling problem. Therefore, the integrated numerical simulation of the excitation system is a complex field-circuit-coupled transient problem, including structural dynamics, eddy current field simulation, and circuit simulation.

The introduction of the freewheeling diode makes the movement process of the mechanism divided into two stages: the discharge of the capacitor and the freewheeling of the diode:

4.2.1. Capacitor Discharge Period. When the switch $S$ is closed, the capacitor begins to discharge. The RLC oscillation occurs on inductance and resistance, and an attenuated oscillating current appears in the loop. According to Kirchhoff's law, an equation of the circuit of the static coil can be established.

$$
\begin{gathered}
R_{c} I_{c}+L_{c} \frac{d I_{c}}{d t}+\frac{d}{d t}\left(M_{c a} I_{a}\right)=U, \\
U=U_{0}-\frac{1}{C} \int_{t_{0}}^{t} I_{c} \mathrm{~d} t, \quad t \geq t_{0},
\end{gathered}
$$

where $R_{c}$ is resistance of the coil loop; $L_{c}$ is the self-inductance of the coil; $I_{c}$ is the current in the coil loop; $M_{c a}$ is the mutual inductance between the coil and the armature; $I_{a}$ is the induced eddy current of the armature; $U$ is the capacitor voltage of the coil; $C$ is the power supply capacitance; $U_{0}$ is the initial voltage of the capacitor; and $t_{0}$ is time when the switch closed.

Transform the last term on the left of equation (10) to

$$
\frac{d}{d t}\left(M_{c a} I_{a}\right)=v_{a} \frac{d M_{c a}}{d z} I_{a}+M_{c a} \frac{d I_{a}}{d t},
$$

and $v_{a}$ is the velocity of the armature, then taking equation (12) into equation (10), we get

$$
R_{c} I_{c}+L_{c} \frac{d I_{c}}{d t}+v_{a} \frac{d M_{c a}}{d z} I_{a}+M_{c a} \frac{d I_{a}}{d t}=U
$$

Similarly, according to Kirchhoff's law, an equation of the circuit of the armature can be established.

$$
R_{a} I_{a}+L_{a} \frac{d I_{a}}{d t}+\frac{d}{d t}\left(M_{a c} I_{a}\right)=0,
$$

where $R_{a}$ is resistance of the armature loop; $L_{c}$ is the inductance of the armature; and $M_{a c}$ is the mutual inductance between the armature and the coil, $M_{a c}=M_{c a}$.

Do the same transformation as equations of the circuit of the static coil, and the governing equation of the mechanism can be given as

$$
\left[\begin{array}{cc}
R_{c} & v_{a} \frac{d M_{c a}}{d z} \\
v_{a} \frac{* d M_{c a}}{d z} & R_{a}
\end{array}\right]\left[\begin{array}{c}
I_{c} \\
I_{a}
\end{array}\right]+\left[\begin{array}{cc}
L_{c} & M_{c a} \\
M_{a c} & L_{a}
\end{array}\right]\left[\begin{array}{c}
\dot{I}_{c} \\
\dot{I}_{a}
\end{array}\right]=\left[\begin{array}{l}
U \\
0
\end{array}\right] .
$$

Use the virtual work principle to calculate the electromagnetic force between the coil and the armature. The magnetic energy stored in the system is the sum of self- 
inductance energy of the coil and the armature, and the mutually inductive energy stored between them. That is,

$$
W_{m}=\frac{1}{2} L_{c} I_{c}^{2}+\frac{1}{2} L_{a} I_{a}^{2}+M_{c a} I_{c} I_{a} .
$$

Thus, the electromagnetic force $f_{z}$ when the aluminium armature moves an infinitesimal displacement $d z$ can be written as

$$
f_{z}=-\frac{\partial W_{m}}{\partial z}=I_{c} I_{a} \frac{d M_{a c}}{d z} .
$$

The structural dynamics equation of the transmission line system is shown as follows:

$$
M \ddot{\delta}+C \dot{\delta}+K \delta=F .
$$

The equations can be reduced to first-order differential equations:

$$
\begin{aligned}
& \dot{\delta}=v, \\
& \dot{v}=M^{-1}(F-C v-K \delta),
\end{aligned}
$$

where $M, C$, and $K$ are the overall mass, damping, and stiffness matrices of the transmission line system, respectively; $F$ is the concentrated force acting on the conductor nodes, $\delta$ is the node displacement column vector, and $v$ is the node velocity column vector.

Take the computed electromagnetic force into equation (20), all equations to be solved in the capacitor discharge stage are shown in the following equation:

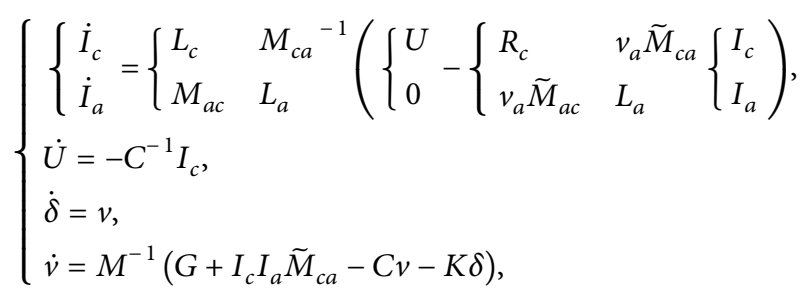

where $v_{a}$ is the speed of the armature, which is consistent with the speed at the excitation point of the line. If the node number at the excitation point is $i$, then $v_{a}=v(i) . \widetilde{M}_{c a}$ is the mutual inductance gradient matrix between the armature and the coil. $G$ is the gravity column vector at each node of the line. The skin effect is considered in the calculation, and the current filament method [28-30] is used to divide the armature and the coil into multiple elements for calculation. Because the transmission line is a geometrically nonlinear system, the internal force $K \delta$ of the system cannot be directly calculated. In this study, the Co-Rotational (CR) Formulation method [31] is used to calculate the internal force of the system.

4.2.2. Diode Freewheeling Period. When the voltage of the capacitor $U$ drops to zero, due to the existence of the freewheeling diode, the current of the capacitor cannot change its direction, and the energy stored in the coil will be freewheeled through the diode. The derivation of the equations is the same as the above capacitor discharge period, and the difference lies in the calculation of coil current and armature induction eddy current, as shown in the following equation:

$$
\left[\begin{array}{c}
\dot{I}_{c} \\
\dot{I}_{a}
\end{array}\right]=-\left[\begin{array}{cc}
L_{c} & M_{c a} \\
M_{a c} & L_{a}
\end{array}\right]^{-1}\left[\begin{array}{cc}
R_{c} & v_{a} \tilde{M}_{c a} \\
v_{a} \tilde{M}_{a c} & L_{a}
\end{array}\right]\left[\begin{array}{c}
I_{c} \\
I_{a}
\end{array}\right] .
$$

For the above two stages, the column vector to be solved is shown below:

$$
Y=\left\{I_{c} I_{a} U \delta v\right\}^{T} .
$$

Fourth-order Runge-Kutta algorithm [29] is used to solve the equations deduced above.

Considering the feasibility of the practical system, the capacitance charging voltage of the electromagnetic repulsive mechanism designed is controlled within $10 \mathrm{kV}$. By adjusting the charging voltage of the capacitor bank, the vibration amplitude of the transmission line can be changed. The optimization design process of electromagnetic excitation device parameters is omitted, and the final design parameters are shown in Table 5.

Simulation calculations are carried out at different time steps, the results show that the calculation results are accurate and reliable when the time step is less than $10^{-5} \mathrm{~s}$. When the charging voltage of the capacitor bank is set to $4 \mathrm{kV}$ and $8 \mathrm{kV}$, respectively, the simulation results under single excitation of the conductor are shown in Figure 13.

When the charging voltage of the capacitor bank is set at $4 \mathrm{kV}$ and $8 \mathrm{kV}$, it can drive the end of the transmission line to move $15 \mathrm{~cm}$ and $28 \mathrm{~cm}$, respectively. After about $60 \mathrm{~ms}$, the coil current and induced eddy current are almost attenuated to 0 . Considering that the excitation period of transmission line galloping is about $3 \mathrm{~s}$, so there will be no interference between the two capacitor bank discharges before and after. It can be seen from the magnetic force-time curve that the electromagnetic force reverses at about $0.1 \mathrm{~s}$, and the reverse electromagnetic force will inject negative energy into the transmission line system. Considering that the coil current is small, it is set to cutoff the coil current using an IGBT after the capacitor bank is discharged $0.1 \mathrm{~s}$ per cycle, so as to prevent the ineffective current of the solenoid coil from reducing the excitation efficiency of the electromagnetic repulsive mechanism.

4.3. Simulation Analysis of the Whole Process. The fourthorder Runge-Kutta algorithm belongs to the explicit method, which has small cost in each time increment but requires relatively small increments. The algorithm does not have the problem of convergence, but the step size needs to be small for this problem, the calculation cost will be expensive, and it takes a long time. In the actual excitation process, most of the time is in the capacitor bank charging period, and there is no electromagnetic force at the excitation point during this period. Therefore, it can be calculated using the Newmark- $\beta$ method when the switch $S$ is turned off. The Newmark- $\beta$ method is an implicit time integration algorithm. Calculation 
TABLE 5: Parameters of the electromagnetic excitation device.

\begin{tabular}{lc}
\hline Item & Parameter \\
\hline Coil material & Copper \\
Coil external radius $(\mathrm{mm})$ & 290 \\
Coil inside radius $(\mathrm{mm})$ & 130 \\
Radial turns of coil & 50 \\
Axial turns of coil & 16 \\
Axial thickness of coil $(\mathrm{mm})$ & 500 \\
Armature material & Aluminium \\
Radial thickness of armature $(\mathrm{mm})$ & 120 \\
Axial thickness of armature $(\mathrm{mm})$ & 100 \\
Capacitance of condenser $(\mathrm{mF})$ & 10 \\
Resistance of condenser $(\mathrm{m} \Omega)$ & 30 \\
Initial clearance $(\mathrm{mm})$ & 100 \\
\hline
\end{tabular}

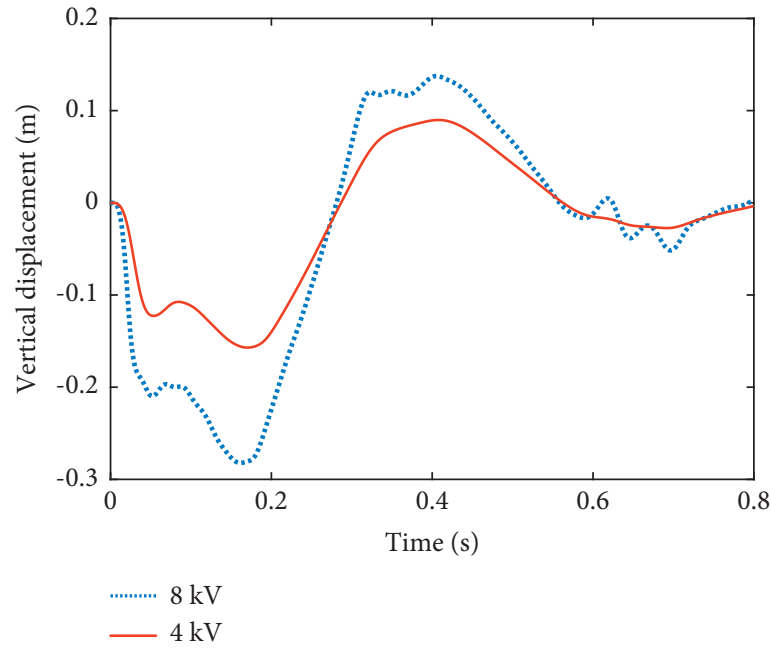

(a)

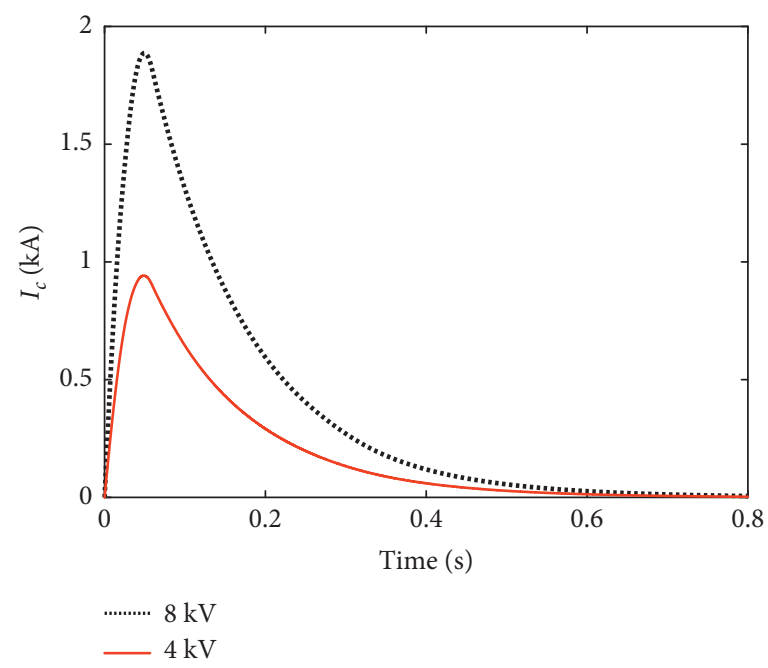

(c)

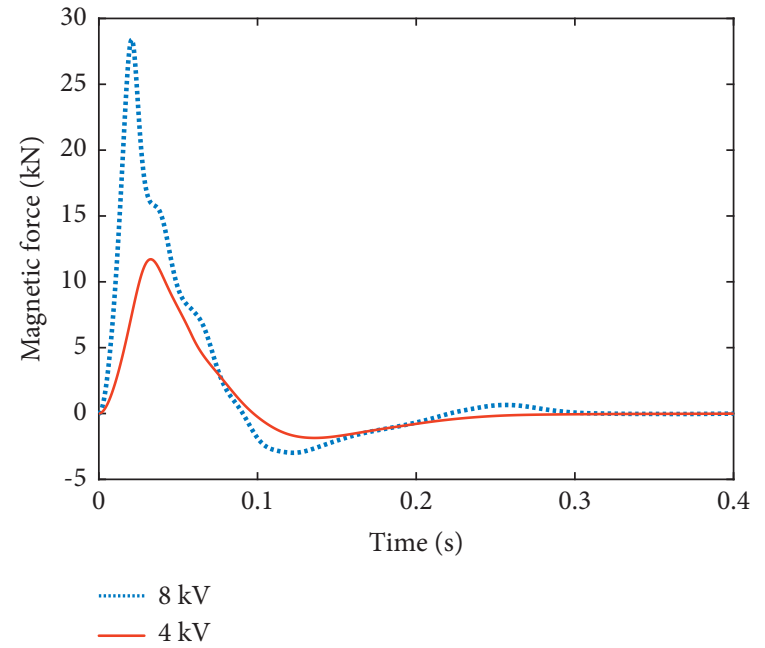

(b)

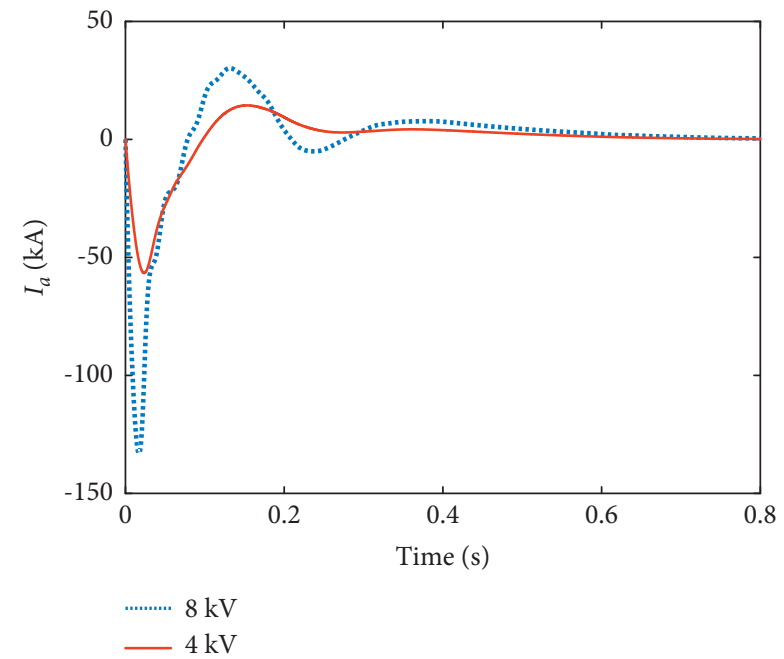

(d)

FiguRE 13: Simulation results of single excitation: (a) Vertical displacement-time curve of the excitation point. (b) Magnetic force-time curve. (c) Current in the coil loop curve with time. (d) Induced eddy current of the armature curve with time.

at each time step requires N-R method iteration, but the step increment is not limited. The two methods can be combined to complete the simulation analysis of the whole process, which will greatly improve the simulation efficiency and reduce the calculation time. The specific simulation flowchart is shown in Figure 14. 


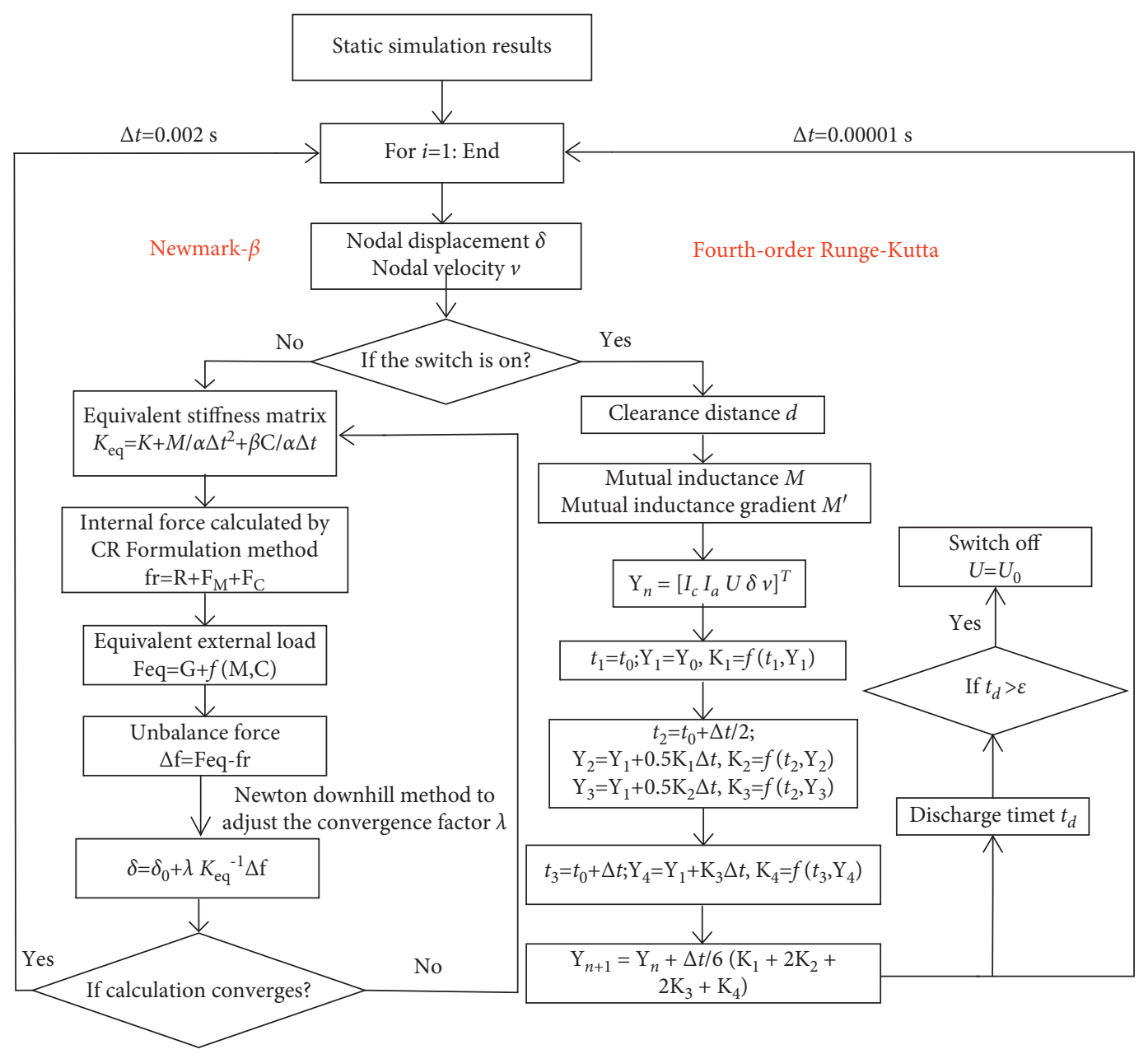

FIGURE 14: Flowchart of the whole process simulation.

The speed, displacement, and other information at the excitation point of the transmission line can be used to judge whether the switch $S$ is on. If it is turned on, the capacitor bank discharges to the coil, and a small time increment is set. The fourth-order Runge-Kutta algorithm is used to solve the problem; when it is judged that the switch $S$ is off, it turns to the charging period of the capacitor bank. The external load of the transmission line system is only the gravity load $G$. Set a large time increment to solve it using the Newmark- $\beta$ method. The Newton downhill method is used to improve the problem that the Newmark- $\beta$ method is difficult to converge in each time step iterative calculation. This calculation will go on and on until the next discharge of the capacitor bank, then the calculation algorithm is converted to the fourth-order Runge-Kutta algorithm.

In order to verify whether the electromagnetic output device designed can excite the actual transmission line galloping and change the vibration amplitude, the initial charging voltage of the capacitor per cycle is set to $4 \mathrm{kV}$ within $0 \sim 150 \mathrm{~s}$, the initial charging voltage of the capacitor is set to $8 \mathrm{kV}$ in $150 \sim 300 \mathrm{~s}$ period. There is no electromagnetic force after $300 \mathrm{~s}$. The whole process of the transmission line vibration is simulated by using the above simulation method, and the magnetic force-time curve is shown in
Figure 15. The vertical displacement-time curve of each measuring point on the conductor is shown in Figures 16(a) 16(d), and the amplitude spectrum is shown in Figure 16(e). The curve of dynamic relative tension coefficient with time under adaptive excitation is shown in Figure 16(f).

From the displacement-time history curve of each measuring point, starting from time 0 , the electromagnetic repulsion mechanism periodically drives the end of the conductor to increase the vibration amplitude. The maximum vibration amplitude of the transmission line in $30 \sim 150 \mathrm{~s}$ is about $1 \sim 1.4 \mathrm{~m}$. The midpoint vibration amplitude is about $0.5 \mathrm{~m}$. After $150 \mathrm{~s}$, the charging voltage becomes $8 \mathrm{kV}$, and the vibration amplitude of each point of the conductor increases rapidly. The maximum vibration amplitude of $180 \sim 300 \mathrm{~s}$ stabilizes at about $1.8 \sim 2.1 \mathrm{~m}$, and the vibration amplitude of the point at midspan is about $1.3 \mathrm{~m}$. After $300 \mathrm{~s}$, the vibration amplitude is continuously reduced because there is no magnetic force acting on the conductor. The vibration amplitude of each point is already less than $0.5 \mathrm{~m}$ at $400 \mathrm{~s}$.

From the spectrum shown in Figure 16(e), the obvious peak of the vertical displacement spectrum of each measuring point is about $0.355 \mathrm{~Hz}$, which is close to the second- 


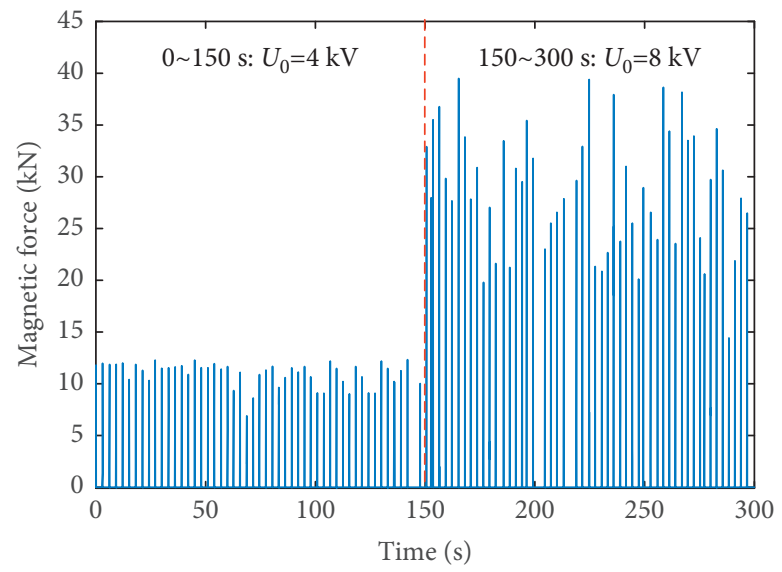

Figure 15: The magnetic force-time curve.

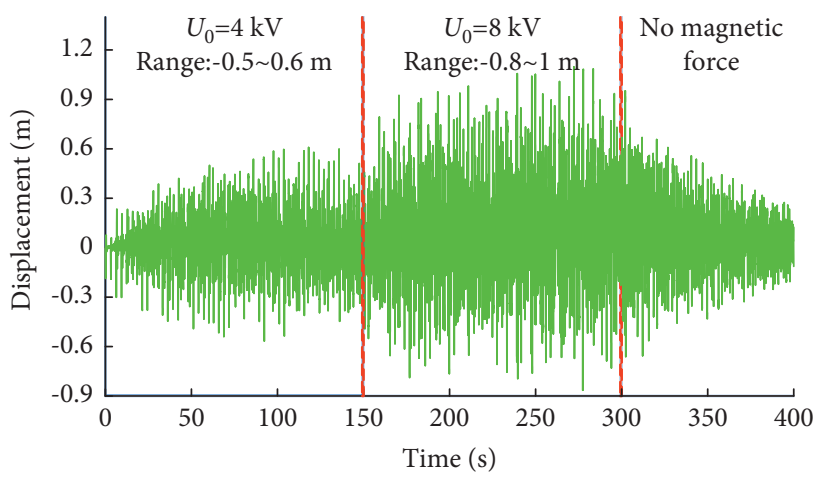

(a)

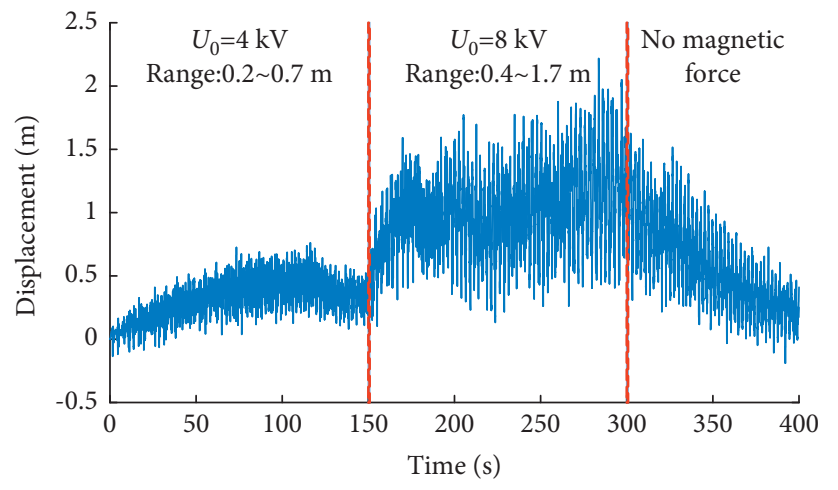

(c)

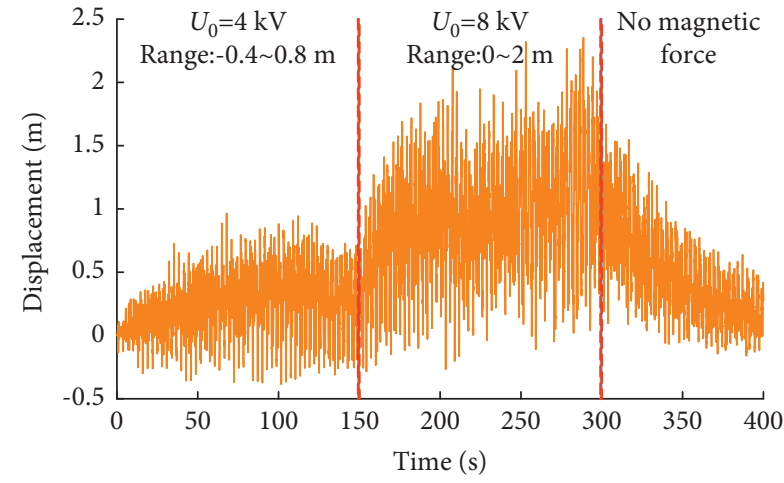

(b)

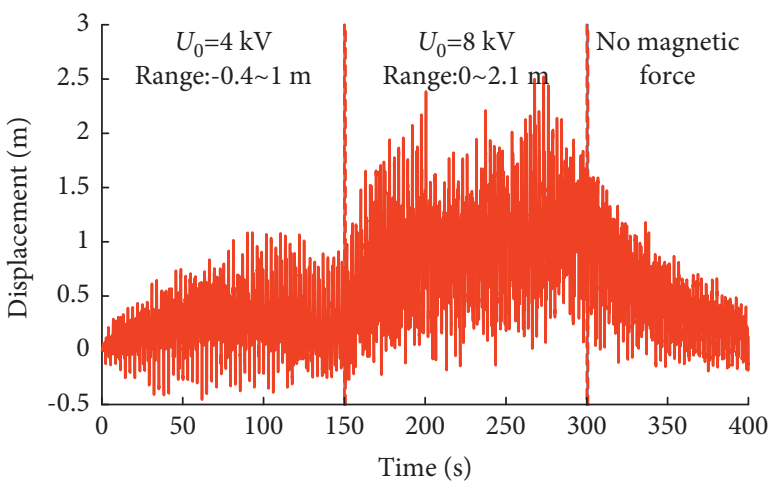

(d)

Figure 16: Continued. 


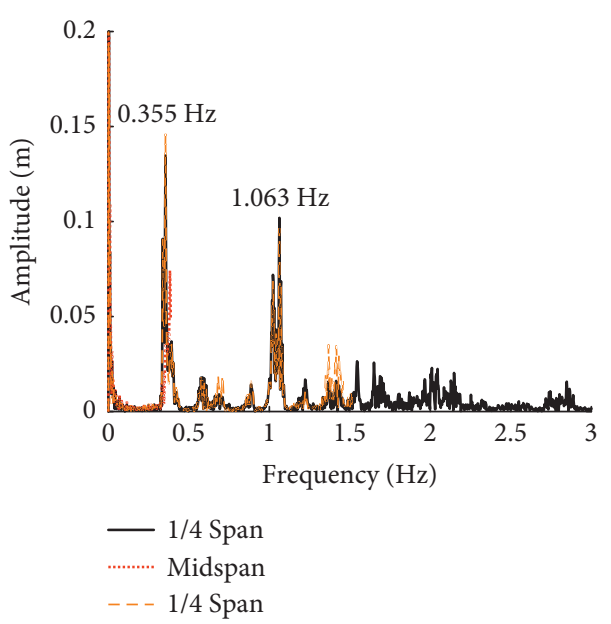

(e)

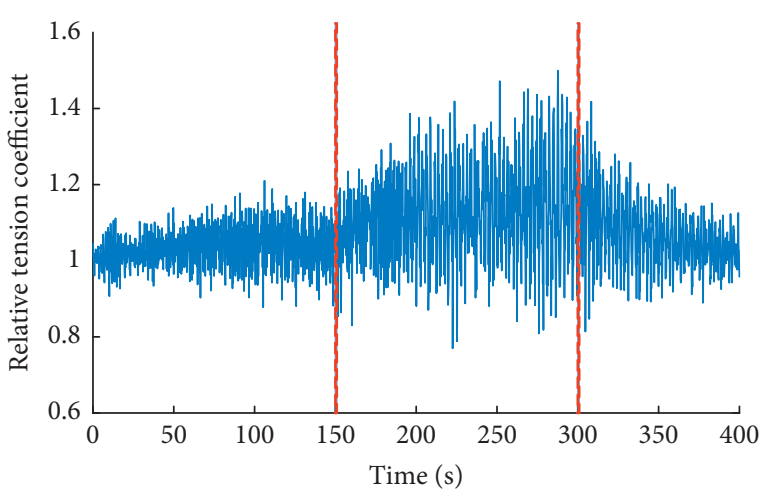

(f)

FiguRE 16: Results of the whole process simulation: (a) Vertical displacement at the excitation point. (b) Vertical displacement at 1/4 point of the line. (c) Vertical displacement at midspan. (d) Vertical displacement at 3/4 point of the line. (e) The amplitude spectrum. (f) Dynamic relative tension coefficient with time.

order natural frequency. Also, there is another obvious peak at $1.063 \mathrm{~Hz}$, which is close to the six-order natural frequency. It shows that the vibration of the conductor under adaptive excitation is mainly a two-loop mode with a six-loop response. From Figure 16(f), the dynamic tension of the conductor increases with the increase in the vibration amplitude. When the capacitor charging voltage is $4 \mathrm{kV}$, the dynamic tension coefficient of the conductor fluctuates between about 0.9 and 1.14; when the capacitor charging voltage is $8 \mathrm{kV}$, the dynamic tension coefficient fluctuates between about 0.82 and 1.4.

In general, the designed electromagnetic output device can successfully simulate the vertical instability of the actual transmission line according to the aforementioned adaptive excitation method, and it can maintain the amplitude of the vibration within a certain range for a long time. By changing the charging voltage of the capacitor bank, the amplitude of the transmission line galloping can be controlled.

\section{Conclusions}

This study proposes an adaptive excitation system for actual transmission line based on the electromagnetic repulsion mechanism. The excitation system can skip the complex process of nonlinear aerodynamic load simulation and directly make static conductors vibrate through mechanical excitation. It can help to establish the controllable transmission line galloping test system, which can be further used in the research of the transmission line galloping and its prevention, such as fatigue damage of transmission tower and armour clamp, effect evaluation of antigalloping device, and so on. It is concluded that

(1) Taking the actual test line as an example, results compared with the field measured data show that the adaptive excitation method proposed in this study can effectively simulate the key characteristics of the actual transmission line galloping, such as amplitude, frequency, vibration mode, and dynamic tension, which can be further used in the research of the transmission line galloping and its prevention.

(2) A high-power controllable electromagnetic output device based on the electromagnetic repulsion mechanism was designed, and the complex fieldcircuit coupled transient model was established. The fourth-order RK algorithm and the Newmark- $\beta$ method are combined to perform numerical calculation, which improves the calculation efficiency.

(3) Results under single excitation show that it can drive the end of the transmission line to move $15 \mathrm{~cm}$ and $28 \mathrm{~cm}$, respectively, when the charging voltage of the capacitor bank is set at $4 \mathrm{kV}$ and $8 \mathrm{kV}$. The coil current and induced eddy current are almost attenuated to 0 after the capacitor discharged for $60 \mathrm{~ms}$, so there will be no interference between the two capacitor bank discharges before and after.

(4) Under periodic excitation of the designed adaptive excitation system, the maximum vertical vibration amplitude of the transmission line is about $1 \sim 1.4 \mathrm{~m}$ and $1.8 \sim 2.1 \mathrm{~m}$ when the charging voltage is $4 \mathrm{kV}$ and $8 \mathrm{kV}$, respectively. The obvious peak of the vertical displacement spectrum is about $0.355 \mathrm{~Hz}$, and the vibration is mainly a two-loop mode. The simulation results show that the designed electromagnetic excitation system can excite and maintain the galloping amplitude within a certain range.

\section{Data Availability}

The data used to support the findings of this study are available from the corresponding author upon request.

\section{Conflicts of Interest}

The authors declare that there are no conflicts of interest regarding the publication of this paper. 


\section{Acknowledgments}

This work was funded by Key R\&D Program of Hubei Province, China (No. 2020BAB108).

\section{References}

[1] Q. F. Wan, Transmission Line Galloping Prevention Technology, China electric power press, Beijing, china, 2016.

[2] G. Piccardo, L. C. Pagnini, and F. Tubino, "Some research perspectives in galloping phenomena: critical conditions and post-critical behavior," Continuum Mechanics and Thermodynamics, vol. 27, no. 1-2, pp. 261-285, 2015.

[3] P. Li, Q. Hong, T. Wu, and H. Cui, "SOF2 sensing by Rhdoped PtS2 monolayer for early diagnosis of partial discharge in the SF6 insulation device," Molecular Physics, vol. 119, no. 11, Article ID e1919774, 2021.

[4] J. P. D. Hartog, "Transmission line vibration due to sleet," Transactions of the American Institute of Electrical Engineers, vol. 51, no. 4, pp. 1074-1076, 1932.

[5] O. Nigol and P. Buchan, "Conductor galloping-Part II Torsional mechanism," vol. PAS-100, no. 2, pp. 708-720, 1981.

[6] P. Yu, A. H. Shah, and N. Popplewell, "Inertially coupled galloping of iced conductors," Journal of Applied Mechanics, vol. 59, no. 1, pp. 140-145, 1992.

[7] H. Matsumiya, T. Nishihara, and T. Yagi, "Aerodynamic modeling for large-amplitude galloping of four-bundled conductors," Journal of Fluids and Structures, vol. 82, pp. 559-576, 2018.

[8] A. Zhou, X. Liu, S. Zhang, F. Cui, and P. Liu, "Wind tunnel test of the influence of an interphase spacer on the galloping control of iced eight-bundled conductors," Cold Regions Science and Technology, vol. 155, pp. 354-366, 2018.

[9] W. Lou, J. Lv, M. F. Huang, L. Yang, and D. Yan, "Aerodynamic force characteristics and galloping analysis of iced bundled conductors," Wind and Structures, vol. 18, no. 2, pp. 135-154, 2014.

[10] J. Li, X. Fu, and H. Li, "Experimental study on aerodynamic characteristics of conductors covered with crescent-shaped ice," Wind and Structures, vol. 29, no. 4, pp. 225-234, 2019.

[11] E. Taib, J. H. Shin, M. K. Kwak, and J. R. Koo, "Dynamic modeling and simulation for transmission line galloping," Journal of Mechanical Science and Technology, vol. 33, no. 9, pp. 1-9, 2019.

[12] Y. M. Desai, A. H. Shah, and N. Popplewell, "Galloping analysis for two-degree-of-freedom oscillator," Journal of Engineering Mechanics, vol. 116, no. 12, pp. 2583-2602, 1990.

[13] Y. M. Desai, P. Yu, and N. Popplewell, "Finite element modelling of transmission line galloping," Computers \& Structures, vol. 57, no. 3, pp. 407-420, 1995.

[14] X. Liu, B. Yan, and H. Zhang, J. Tang, "Nonlinear finite element analysis for iced bundled conductor," Journal of Vibration and Shock, vol. 29, no. 6, pp. 129-133, 2010, https:// www.researchgate.net/scientific-contributions/S-Zhou2089068796.

[15] L. Li, Y. Chen, Z. Xia, and H. Cao, "Nonlinear numerical simulation study of iced conductor galloping," Journal of Vibration and Shock, vol. 30, no. 8, pp. 107-111, 2011.

[16] J. Hu, B. Yan, S. Zhou, and H. Zhang, "Numerical investigation on galloping of iced quad bundle conductors," IEEE Transactions on Power Delivery, vol. 27, no. 2, pp. 784-792, 2012.
[17] L. Zhou, B. Yan, L. Zhang, and S. Zhou, "Study on galloping behavior of iced eight bundle conductor transmission lines," Journal of Sound and Vibration, vol. 362, pp. 85-110, 2016.

[18] M. Cai, B. Yan, X. Lu, and L. Zhou, "Numerical simulation of aerodynamic coefficients of iced-quad bundle conductors," IEEE Transactions on Power Delivery, vol. 30, no. 4, pp. 1669-1676, 2015.

[19] C. Wu, Z. Ye, B. Zhang, Z. Lv, Q. Li, and B. Yan, "Study on galloping oscillation of iced twin bundle conductors considering the effects of variation of aerodynamic and electromagnetic forces," Shock and Vibration, vol. 2020, Article ID 6579062, 18 pages, 2020.

[20] D. Wu, S. Yang, L. Tao et al., "Full-scale reconstruction for transmission line galloping curves based on attitudes sensors," Mathematical Problems in Engineering, vol. 2018, Article ID 1095842, 11 pages, 2018.

[21] P. V. Dyke and A. Laneville, "Galloping of a single conductor covered with a D-section on a high-voltage overhead test line," Journal of Wind Engineering and Industrial Aerodynamics, vol. 96, pp. 1141-1151, 2008.

[22] C. B. Gurung, H. Yamaguchi, and T. Yukino, "Identification and characterization of galloping of Tsuruga test line based on multi-channel modal analysis of field data," Journal of Wind Engineering and Industrial Aerodynamics, vol. 91, pp. 903924, 2003.

[23] M. Cai, Q. Xu, L. Zhou, X. Liu, and H. Huang, “Aerodynamic characteristics of iced 8-bundle conductors under different turbulence intensities," KSCE Journal of Civil Engineering, vol. 23, no. 11, pp. 4812-4823, 2019.

[24] M. Lu, G. Fu, D. Yan, and L. Wang, "Galloping fault analysis and computation for $500 \mathrm{kV}$ double lines in one tower in Henan Grid," High Voltage Engineering, vol. 40, no. 5, pp. 1391-1398, 2014.

[25] L. Zhang, J. Ruan, Z. Du, Y. Gan, G. Li, and W. Zhou, "Shortterm failure warning for transmission tower under land subsidence condition," IEEE ACCESS, vol. 8, pp. 1045510465, 2020.

[26] X. G. Lu, Numerical Simulation Study on Anti-galloping of Six Bundle Conductors in Test Transmission Line, Chongqing University, Chongqing, China, 2014.

[27] L. Zhou, B. Yan, X. Yang, and Z. Lv, "Galloping simulation of six-bundle conductors in a transmission test line," Journal of Vibration and Shock, vol. 33, no. 9, pp. 6-11, 2014.

[28] S. Liu, J. Ruan, Y. Peng, Y. Zhang, and Y. Zhang, "Improvement of current filament method and its application in field-circuit analysis of induction coil gun," Proceedings of the CSEE, vol. 30, no. 30, pp. 128-134, 2010.

[29] L. Zhang, J. Ruan, D. Huang, and P. Li, "Study on the design and movement characteristics simulation of a fast repulsion mechanism based on double-coil structure," Transactions of China Electrotechnical Society, vol. 33, no. 2, pp. 255-264, 2018.

[30] Y. Zhang, Y. Wang, and J. Ruan, "Capacitor-driven coil-gun scaling relationships," IEEE Transactions on Plasma Science, vol. 39, no. 1, pp. 220-224, 2011.

[31] K. Hsiao and W. Lin, "Co-rotational formulation for geometric nonlinear analysis of doubly symmetric thin-walled beams," Computer Methods in Applied Mechanics and Engineering, vol. 190, no. 45, pp. 6023-6052, 2001. 